\title{
Drugs that inhibit TMEM16 proteins block SARS-CoV-2 spike-induced syncytia
}

https://doi.org/10.1038/s41586-021-03491-6

Received: 23 July 2020

Accepted: 25 March 2021

Published online: 7 April 2021

Check for updates

\author{
Luca Braga ${ }^{1,9}$, Hashim Ali, ${ }^{1,9}$, Ilaria Secco', Elena Chiavacci', Guilherme Neves ${ }^{2,3}$, \\ Daniel Goldhill ${ }^{4}$, Rebecca Penn ${ }^{4}$, Jose M. Jimenez-Guardeño ${ }^{5}$, Ana M. Ortega-Prieto ${ }^{5}$, \\ Rossana Bussani ${ }^{6}$, Antonio Cannatà', Giorgia Rizzari', Chiara Collesi ${ }^{6,7}$, Edoardo Schneider ${ }^{1,7}$, \\ Daniele Arosio ${ }^{8}$, Ajay M. Shah', Wendy S. Barclay ${ }^{4}$, Michael H. Malim ${ }^{5}$, Juan Burrone ${ }^{2,3}$ \& \\ Mauro Giacca ${ }^{1,6,7 凶}$
}

\begin{abstract}
COVID-19 is a disease with unique characteristics that include lung thrombosis ${ }^{1}$, frequent diarrhoea ${ }^{2}$, abnormal activation of the inflammatory response ${ }^{3}$ and rapid deterioration of lung function consistent with alveolar oedema ${ }^{4}$. The pathological substrate for these findings remains unknown. Here we show that the lungs of patients with COVID-19 contain infected pneumocytes with abnormal morphology and frequent multinucleation. The generation of these syncytia results from activation of the SARS-CoV-2 spike protein at the cell plasma membrane level. On the basis of these observations, we performed two high-content microscopy-based screenings with more than 3,000 approved drugs to search for inhibitors of spike-driven syncytia. We converged on the identification of 83 drugs that inhibited spike-mediated cell fusion, several of which belonged to defined pharmacological classes. We focused our attention on effective drugs that also protected against virus replication and associated cytopathicity. One of the most effective molecules was the antihelminthic drug niclosamide, which markedly blunted calcium oscillations and membrane conductance in spike-expressing cells by suppressing the activity of TMEM16F (also known as anoctamin 6), a calcium-activated ion channel and scramblase that is responsible for exposure of phosphatidylserine on the cell surface. These findings suggest a potential mechanism for COVID-19 disease pathogenesis and support the repurposing of niclosamide for therapy.
\end{abstract}

One of the defining features of coronavirus biology is the coordinated process by which the virus binds and enters the host cell, which involves both docking to receptors at the cell surface $\left(\mathrm{ACE} 2\right.$ for SARS-CoV2 ${ }^{5}$ ), and proteolytic activation of the spike protein by host encoded proteases at two distinct sites ${ }^{6}$. One activation step is spike cleavage at the S1-S2 boundary, which can occur either before or after receptor binding. A second proteolytic activation exposes the S2 portion, and primes $\mathrm{S} 2$ for fusion of virus and cellular membranes. The protease priming event at this S2' site and subsequent fusion can occur after endocytosis, in which cleavage is carried out by endosomal low $\mathrm{pH}$-activated proteases such as cathepsin B and cathepsin $\mathrm{L}^{7}$, or at the plasma membrane, where cleavage can be mediated by TMPRSS $2^{8-10}$. The spike proteins of MERS-CoV and SARS-CoV-2 possess a multibasic amino acid sequence at the $\mathrm{S} 1-\mathrm{S} 2$ interface, which is not present in SARS-CoV ${ }^{11}$, that also allows cleavage by the ubiquitously expressed serine protease furin ${ }^{12-14}$. As a consequence, cells that express MERS-CoV and SARS-CoV-2 spike protein at the plasma membrane can fuse with other cells that express the respective receptors and form syncytia.

\section{Pneumocyte syncytia in COVID-19 lungs}

We examined the organs of 41 consecutive patients who died from COVID-19 in the period from March to May 2020 at the University Hospital in Trieste, Italy. Detailed post-mortem analysis of these patients has previously been reported ${ }^{15}$. In addition to diffuse alveolar damage, frequent thrombosis and extensive fibrotic substitution, a peculiar finding was the presence-inalmost $90 \%$ of these patients-of atypical cells with the characteristic of syncytia, showing a large cytoplasm containing a variable number of nuclei, ranging from 2 to more than 20 (shown in Fig. 1a for 4 patients). Most of these syncytial cells were bona fide pneumocytes, as they expressed two pneumocyte-specific markers(napsinand surfactant B), and were positive for viral RNAby in situ hybridization(ExtendedDataFig.1a,b).

\section{Fusogenic properties of spike protein}

The presence of fused cells in the lungs of patients with COVID-19 probably results from the fusogenic activity of the SARS-CoV-2 spike

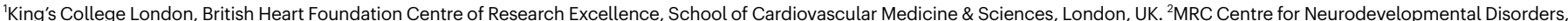
Institute of Psychiatry, Psychology and Neuroscience, King's College London, London, UK. ${ }^{3}$ Centre for Developmental Neurobiology, Institute of Psychiatry, Psychology and Neuroscience, King's College London, London, UK. ${ }^{4}$ Department of Infectious Diseases, Imperial College London, London, UK. ${ }^{5}$ Department of Infectious Diseases, School of Immunology \& Microbial Sciences, King's College London, London, UK. ${ }^{6}$ Department of Medical, Surgical and Health Sciences, University of Trieste, Trieste, Italy. ${ }^{7}$ International Centre for Genetic Engineering and Biotechnology (ICGEB), Trieste, Italy. ${ }^{8}$ Istituto di Biofisica (IBF), Consiglio Nazionale delle Ricerche (CNR), Trento, Italy. ${ }^{9}$ These authors contributed equally: Luca Braga, Hashim Ali.

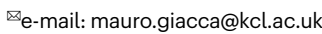


protein. In vitro, the expression of codon-optimized spike cDNA in Vero cells led to the conspicuous presence of syncytia (Fig. 1b). The presence of spike protein on the plasma membrane also triggered the fusion of heterologous cells when these expressed the ACE2 receptor. Supplementary Video 1 shows the effect of co-culturing, for $12 \mathrm{~h}$, spike-transfected human U2OS cells (which have undetectable levels of ACE2) with enhanced green fluorescent protein (eGFP)-transfected Vero cells. Progressive, heterologous cell fusion continued during the 12-h observation period.

At higher magnification, spike-expressing Vero cells and spike-positive syncytia projected a notable number of plasma membrane protrusions, showing filopodia extensions and contacting the plasma membrane of neighbouring cells (Extended Data Fig. 1c). These spike-expressing cells and syncytia displayed sudden calcium $\left(\mathrm{Ca}^{2+}\right)$ transients in their cytoplasm, as visualized by transfecting the GCaMP6s fluorescent $\mathrm{Ca}^{2+}$ sensor (Supplementary Videos 2,3).

In contrast to the SARS-CoV-2 spike protein, no formation of syncytia was observed when spike from SARS-CoV was expressed, whereas MERS-CoV spike was also markedly syncytiogenic (Extended Data Fig. 1d, e).

\section{Screening for drugs that block syncytia}

We wanted to find clinically approved drugs that inhibit SARS-CoV-2 spike-mediated cell fusion. We developed two assays for high-throughput screening (HTS) using high-content imaging. The first was based on heterologous fusion between Vero and spike-expressing U2OS cells (cell fusion inhibition assay (CFIA)), whereas the second was based on direct expression of spike protein in Vero cells (syncytia inhibition assay (SIA)). With these two assays, we screened two FDA/ EMA-approved drug libraries (Prestwick Chemical Library and The Spectrum Collection, MicroSource (MS) Discovery), totalling 3,825 drugs. As 776 drugs are common to the two libraries, this amounts to 3,049 different small molecules.

The CFIA and its results are shown in Extended Data Fig. 2a-g. For the SIA screening, we expressed spike protein for $15 \mathrm{~h}$, incubated the cells with the drugs for an additional $24 \mathrm{~h}$ and then imaged and quantified syncytia (Fig. 1c). This screening revealed 57 drugs from the Prestwick and 84 drugs from the MS Discovery library that inhibited spike-mediated fusion with a $z$ score of less than $-1.96(0.025 \%$ tail of the distribution), of which 37 and 47, respectively, had $z$ scores $<-2.58(0.005 \%$ tail) (shown in red in Fig. 1e and listed in Supplementary Table 2). All wells treated with dimethylsulfoxide (DMSO) for either library had a $z$ score in the \pm 0.25 range. The distribution of the results for each of the two libraries is shown in Extended Data Fig. 3a, b. As for CFIA, there was a significant correlation of effect for the common drugs in the two libraries (Extended Data Fig. $3 c)\left(P<0.0001, R^{2}=0.18\right)$. Representative images from the screening are shown in Fig. 1 for niclosamide, the top hit in the Prestwick and the second in the MS Discovery library, and in Extended Data Fig. 3d for other effective drugs. Dose-response curves for syncytia inhibition for three selected drugs (niclosamide, clofazimine and salinomycin) are shown in Extended Data Figs. $3 \mathrm{e}$ for Vero and HEK293 cells. Extended Data Fig. 4a shows the results of the SIA screening according to therapeutic drug classes.

\section{Antiviral effect of drugs}

The CFIA and SIA screenings cumulatively identified 83 drugs a $z$ score of less than-2.58 (Extended Data Fig. 4b). The choice for further studies took in consideration the following criteria: (1) common inhibitory effect in the two screenings; (2) relative efficacy within specific drug classes; and (3) pharmacological suitability to clinical application. On the basis of these criteria, we assessed the effect of 43 drugs on SARS-CoV-2 infection (drug list in Extended Data Fig. 5a). Vero cells were infected with SARS-CoV-2 strain IC19/2020 (median tissue culture infectious dose $\left(\mathrm{TCID}_{50}\right)$ of 100 per well) in the presence of $10 \mu \mathrm{M}$ of the drugs in 96-well plates. The ability of the drugs to protect cells from viral cytopathic effects was analysed after 5 days (Extended Data Fig. 5b). Of the most effective drugs, we selected one antihistamine (deptropine), one antidepressant (sertraline) and the antileprotic antibiotic clofazimine for further studies. Niclosamide and salinomycin, which scored as cytotoxic at $10 \mu \mathrm{M}$ in the absence of the virus (not shown), were also shortlisted, as these drugs were among the most effective in the SIA screening.

The five selected drugs were further assessed for cell protection against virus-induced cell death in a range of doses, followed by the analysis of cell survival after five days. Niclosamide, clofazimine and salinomycin were the most effective in this cell protection assay (Extended Data Fig. 5c) and were thus chosen for further testing of antiviral function.

Vero cells were infected in triplicate with SARS-CoV-2 (multiplicity of infection (MOI) 0.05) in the presence of escalating drug concentrations; culture supernatants were collected $48 \mathrm{~h}$ after viral challenge and the production of infectious virus was determined by plaque assay (Fig. 2a). Niclosamide and salinomycin displayed similar half-maximal inhibitory concentration $\left(\mathrm{IC}_{50}\right.$ ) values of $0.34 \mu \mathrm{M}$ and $0.22 \mu \mathrm{M}$, respectively, whereas clofazimine was approximately 10 -fold less potent $\left(\mathrm{IC}_{50}\right.$ of $2.56 \mu \mathrm{M}$ ). All three drugs also inhibited viral replication in respiratory Calu-3 cells (Extended Data Fig. 5d). Representative images of Calu-3 syncytia infected with SARS-CoV-2 are shown in Extended Data Fig. 5e. Of note, the cells still infected in the presence of niclosamide were no longer syncytial (Extended Data Fig. 5f).

\section{Anti-syncytial drugs block calcium release}

We wanted to understand the mechanism(s) by which the selected drugs inhibited syncytia formation. We were intrigued by the observation that our assays had selected for specific drug classes. In particular, there were 11 antipsychotics, 8 antidepressants and 5 first-generation histamine $1\left(\mathrm{H}_{1}\right)$ receptor antagonists among the top selected drugs. A common characteristic of these molecules is their capacity to regulate intracellular $\mathrm{Ca}^{2+}$ levels. The $\mathrm{H}_{1}$ receptor, $\mathrm{M} 1, \mathrm{M} 2$ and $\mathrm{M} 5$ muscarinic receptors, and the $5-\mathrm{HT}_{2}$ serotonin receptors signal through a $G_{q} \alpha$ subunit to activate phospholipase $C-\beta$ (PLC- $\beta$ ), which in turn hydrolyses PIP2 to generate Ins $(1,4,5) \mathrm{P}_{3}$ (also known as $I \mathrm{P}_{3}$ ). IP 3 acts as a second messenger to activate $\mathrm{Ca}^{2+}$ release into the cytoplasm from the endoplasmic reticulum (ER) stores after binding to the $\mathrm{IP}_{3}$ receptor $^{16}$. Besides $\mathrm{H}_{1}$ receptor antagonists and anticholinergics, phenothiazine antipsychotics and other tricyclics also act, to a different extent, on these receptors. Cyclosporin A forms a complex with cyclophilin, which-in platelets-inhibits store-operated- $\mathrm{Ca}^{2+}$ entry into cells through $\mathrm{Ca}^{2+}$ release-activated $\mathrm{Ca}^{2+}$ channels ${ }^{17}$. Finally, the $\mathrm{L}$-type $\mathrm{Ca}^{2+}$ channel blockers and most of the tricyclic antidepressant ${ }^{18}$ inhibit the voltage-dependent L-type calcium channels, which are also expressed in epithelial cells, including HEK293 cells ${ }^{19}$.

Combining these considerations, we wanted to explore the dynamics of $\mathrm{Ca}^{2+}$ levels in cells expressing spike and during cell fusion. We performed time-lapse imaging of Vero cells that express the calcium indicator GCaMP $6 \mathrm{~s}^{20}$, co-cultured with $\mathrm{U} 2 \mathrm{OS}$ cells expressing spike and mCherry fluorescent protein. We observed that the spike-expressing cells as well as the heterologous syncytia they formed had numerous oscillations in intracellular $\mathrm{Ca}^{2+}$ levels (Supplementary Video 4; individual frames in Fig. 2b). To obtain a quantitative measurement of these $\mathrm{Ca}^{2+}$ oscillations, we expressed GCaMP6s in Vero cells, with or without spike protein, and imaged these cells for $400 \mathrm{~min}$. Over this period, the cells expressing spike protein progressively fused and had frequent $\mathrm{Ca}^{2+}$ oscillations (Supplementary Video 5, movie without drugs and individual frames in Fig. 2c). The oscillation traces for more than 50 cells (or syncytia in the case of fused cells) are overlaid for each condition (control or spike) in Fig. 2d. The presence of spike protein increased the 
a

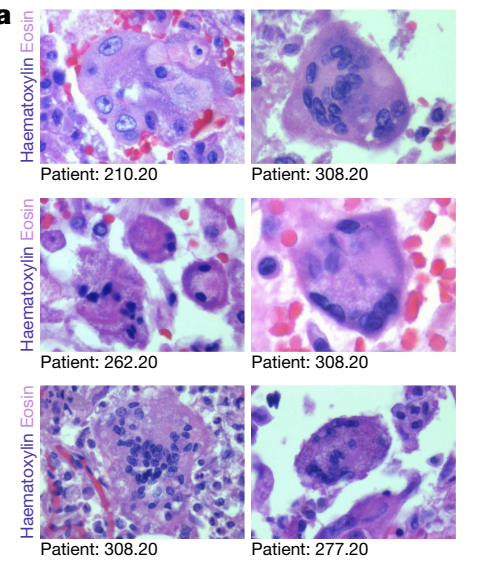

d

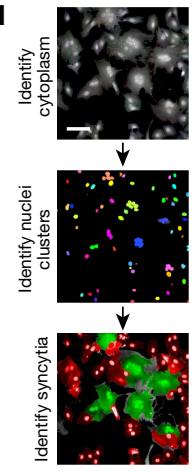

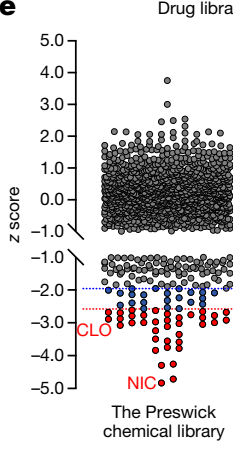

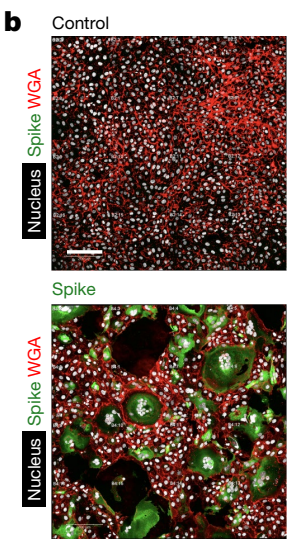

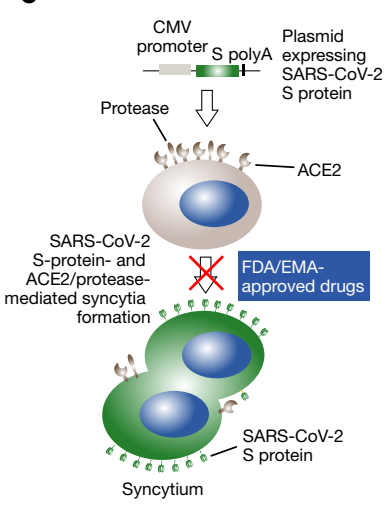$$
\text { f }
$$

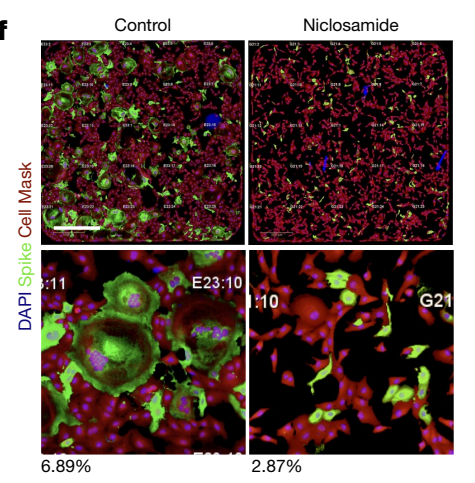

Fig. 1 | Drugs inhibiting SARS-CoV-2 spike-induced syncytia. a, Post-mortem histological analysis of lungs of patients with COVID-19 showing multinucleated syncytia. Original magnification, $\times 40$. Further characterization of these patients has previously been reported ${ }^{15}$.b, Formation of syncytia after $24 \mathrm{~h}$ expression of spike in Vero cells. Nuclei in white; cell contours in red using wheat-germ agglutinin (WGA); spike protein in green. Scale bars, $200 \mu \mathrm{m}$. c, SIA screening. S, spike.d, Image analysis workflow; syncytia were defined as cells showing a cluster of nuclei with an area at least five times larger than the average of the area of non-fused cells. Scale bar, $500 \mu \mathrm{m}$. e, Results of SIA screening. The percentage of syncytia normalized on total cells is plotted as a $z$ score. Compounds with a $z$ score $\leq-2.58$ (red dotted line, $0.005 \%$ tail) are shown in red; those between $\leq-1.96(0.025 \%$ tail, blue dotted line) and -2.58 area in blue. Four drugs that were further studied with viral infection are indicated. CLO, clofazimine; NIC, niclosamide; SAL, salinomycin; SER, sertraline.f, Effect of niclosamide on syncytia. Spike-positive syncytia are in green; nuclei are in blue; cell body is in red using HCS CellMask DeepRed. The percentage of nuclei within in syncytia over total nuclei is shown at the bottom. Scale bar, $500 \mu \mathrm{m}$. Numbers on some of the images indicate the screening well. Images are representative of 25 per well; screening was performed in duplicate. amplitude of $\mathrm{Ca}^{2+}$ transients in individual cells $(P<0.01)$ (Extended Data Fig. 6a), without a significant difference in frequency, which suggests that the expression of spike amplifies spontaneous $\mathrm{Ca}^{2+}$ transients. The expression of spike protein from SARS-CoV was ineffective (Extended Data Fig. 7a, b), whereas spike protein from MERS-CoV also induced $\mathrm{Ca}^{2+}$ oscillations. Both $1 \mu \mathrm{M}$ niclosamide and $5 \mu \mathrm{M}$ clofazimine markedly blunted both the amplitude and frequency of the $\mathrm{Ca}^{2+}$ oscillations in cells treated with SARS-CoV-2 spike protein $(P<0.01)$ (Fig. 2 d, Extended Data Fig. 6b). Salinomycin, while still inhibiting syncytia formation, was ineffective in these experiments. Representative movies showing these results are in Supplementary Video 5.

Cells treated for $400 \mathrm{~min}$ with thapsigargin or cyclopiazonic acid, two non-competitive inhibitors of the sarco/endoplamic reticulum $\mathrm{Ca}^{2+}$ ATPase (SERCA), which cause ER $\mathrm{Ca}^{2+}$ store depletion $^{21}$, abolished these oscillations, similar to the removal of $\mathrm{Ca}^{2+}$ from the cell culture medium (Extended Data Fig. 6c, d). These results are consistent with the conclusion that the ER is the main source of $\mathrm{Ca}^{2+}$ release induced by the SARS-CoV-2 spike protein. Of note, cell treatment with thapsigargin or cyclopiazonic acid also inhibited the expansion of syncytia while not affecting cell viability (Fig. 3a, b, Supplementary Video 6).

\section{TMEM16F is required for syncytia}

A possible explanation of these findings was provided by the observation that niclosamide is a potent inhibitor of the $\mathrm{Ca}^{2+}$-activated TMEM16 family of chloride channels and scramblases ${ }^{22}$. We investigated the levels of the 10 members of this family in several cell lines and in primary bronchial human airway epithelial cells (Extended Data Fig. 8a). We found that TMEM16F, which functions both as a non-specific ion channel and a lipid scramblase responsible for phosphatidylserine externalization onto the outer leaflet of the plasma membrane ${ }^{23}$, was expressed in all cells and that its levels further increased after spike expression (Extended Data Fig. 8b).

We wondered whether the activity of TMEM16F at the membrane was affected by spike protein. We performed whole-cell voltage-clamp recordings of HEK293 cells to measure the endogenous currents carried by this channel. We recorded small but clearly detectable outwardly rectifying currents in response to voltage ramps. This current required high intracellular $\mathrm{Ca}^{2+}(28 \mu \mathrm{M})$, was blunted by the targeted knockdown of TMEM16F (Fig. 3d; RNA and protein levels to confirm knockdown are in Extended Data Fig. 9a for all the investigated cell types), was blocked by the TMEM16A and TMEM16F inhibitor benzbromarone $(10 \mu \mathrm{M})$ $(P<0.01)$ and was reduced at lower intracellular $\mathrm{Ca}^{2+}(0.5 \mu \mathrm{M})$ (Extended Data Fig. 10a). These results suggest that this current is carried, at least in part, by TMEM $16 \mathrm{~F}$ channels. We found that acute administration of niclosamide $(2 \mu \mathrm{M})$ readily blocked this current $(P<0.01)$, whereas both clofazimine $(5 \mu \mathrm{M})$ and salinomycin $(5 \mu \mathrm{M})$ had no significant direct effect (Fig. 3c). Notably, we found that HEK293 cells expressing spike and ACE2 showed an increased current in response to voltage ramps $(P<0.05)$ (Fig. 3e), reflecting either an increase in TMEM16F expression 


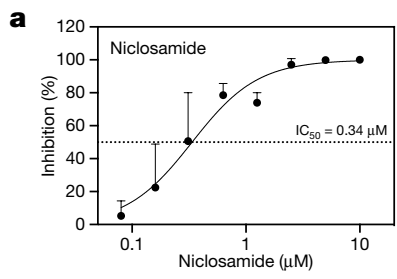

b Vero-GCaMP6s

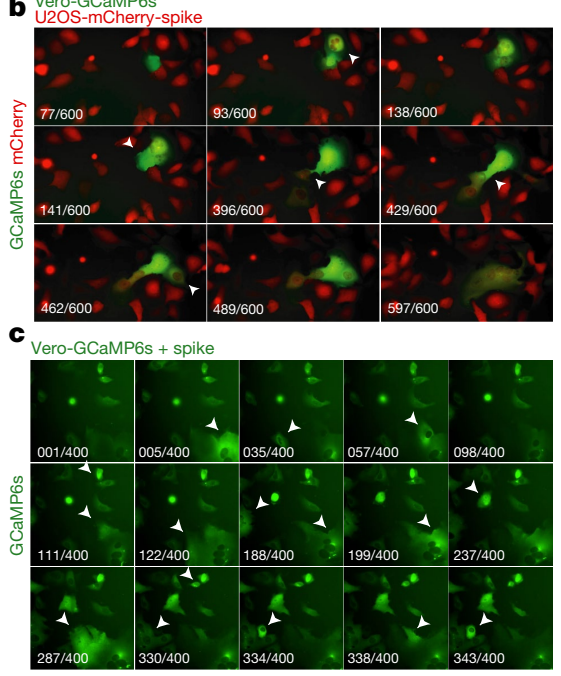

Fig. 2 | Effects of drugs on SARS-CoV-2 replication and intracellular calcium oscillations. a, Inhibition of SARS-CoV-2 replication. Vero E6 cells were treated with the indicated drug concentrations for $2 \mathrm{~h}$, followed by the addition of SARS-CoV-2 (MOI 0.05). After $1 \mathrm{~h}$, cells were washed and cultured in drug-containing medium for $48 \mathrm{~h}$. Virus production in the culture supernatants was quantified by plaque assay using Vero E6 cells. Data are mean \pm s.d.; $n=3$. b, Representative frames (from of a total of 600) from a 12-h time-lapse movie of a co-culture of Vero cells expressing the GCaMP6s Ca ${ }^{2+}$ sensor and U2OS cells transfected with spike protein and mCherry. Arrowheads indicate $\mathrm{Ca}^{2+}$ oscillations in GCaMP6s-ACE2-expressing cells when fusing to spike-expressing cells. See Supplementary Video 4 for time-lapse movie.

(Extended Data Fig. 8b) or a modulation of channel activity. None of the investigated drugs changed the expression levels of either TMEM16A or TMEM16F (Extended Data Fig. 8c).

Collectively, these results indicate that SARS-CoV-2 spike leads to the activation of TMEM16 proteins and that niclosamide inhibits this activity. We thus wanted to explore the relationship between this effect and the suppression of syncytia. First, we found that the downregulation of TMEM16F inhibited $\mathrm{Ca}^{2+}$ transients induced by spike (Extended Data Fig. 7c, d). In these experiments, a short interfering RNA (siRNA) against $A C E 2$ also had a similar suppressive effect, again underlining the relationship between $\mathrm{Ca}^{2+}$ oscillations, TMEM16F function and spike-mediated cell-cell fusion. Then, we observed that the downregulation of TMEM16F almost completely suppressed externalization of phosphatidylserine in Vero cells treated with the $\mathrm{Ca}^{2+}$ ionophore ionomycin $(10 \mu \mathrm{M})$ (Fig. 3f, g, Extended Data Fig. 10b, c), which indicates that TMEM16F is the main cellular scramblase responsive to $\mathrm{Ca}^{2+}$ in these cells. In line with these observations, treatment with either niclosamide or clofazimine for $1 \mathrm{~h}$ significantly reduced the levels of externalized phosphatidylserine in response to ionomycin (Fig. 3h, i, Extended Data Fig. 10d). More than $95 \%$ of cell nuclei remained negative to propidium iodide in these experiments, ruling out cell apoptosis (not shown). Consistent with TMEM16F activation, several spike-induced syncytia exposed phosphatidylserine on their plasma membrane (Extended Data Fig. 10e).

To confirm the specific involvement of TMEM16F in syncytia formation, we knocked down ACE2, TMEM16A and TMEM16F in Vero,

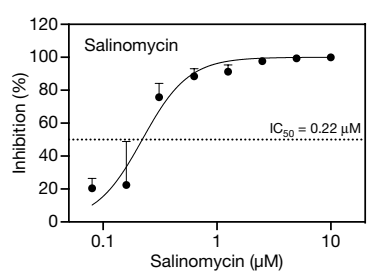

d
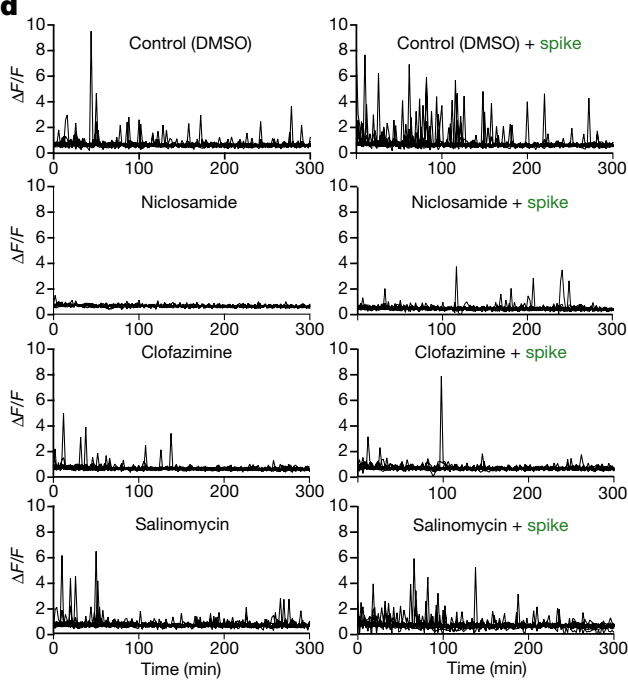

c, $\mathrm{Ca}^{2+}$ oscillations during syncytia formation. Representative frames (from of a total of 400) from a 12-h time lapse movie of spike-expressing Vero cells. Arrowheads indicate cells progressively fusing to a syncytium and show intense $\mathrm{Ca}^{2+}$ spikes. See Supplementary Video 5 for time-lapse movie (movie in the top left panel, labelled 'DMSO'). d, GCaMP intensity over time. Vero cells were co-transfected with GCaMP6s and either a control or a spike-expressing vector and treated with the indicated drugs. Data are expressed as change in fluorescence $(\Delta F / F)$ over time ( $\mathrm{min})$; every line is 1 of at least $12180-\mu \mathrm{m}^{2}$ regions of interest per condition, representing a group of $4 \mathrm{GCaMP}$-positive cells on average. See Supplementary Video 5 for representative movies.

HEK293 or Calu-3 cells. The downregulation of TMEM16F blunted syncytia formation in spike-expressing cells, similar to an anti-ACE2 siRNA (Fig. 3j, k). An analogous inhibitory effect of TMEM16F knockdown was observed in Calu-3 cells (Extended Data Fig. 11a-d). Of interest for future investigation, TMEM16F knockdown had no apparent effect on syncytia induced by the MERS-CoV spike protein (Extended Data Fig. 11e, f). By contrast, overexpression of TMEM16F, but not of TMEM16A, significantly stimulated SARS-CoV-2 spike-induced syncytia (Fig. 3l, m, Extended Data Fig. 11g). Finally, we observed that Calu-3 cells in which TMEM16F was downregulated showed significantly impaired infectious SARS-CoV-2 replication (visualization of infected cells with anti-spike and anti-nucleocapsid antibodies in Fig. 3n, p).

\section{Discussion}

We envisage at least three mechanisms by which spike can activate TMEM16 proteins. This can occur directly on the spike-expressing (infected) cells in cis or after binding to ACE2 and activating protease in trans, or indirectly through the activation of $\mathrm{Ca}^{2+}$ release. As far as the interaction between $\mathrm{Ca}^{2+}$ levels and TMEM16 proteins is concerned, TMEM16 activation by SARS-CoV-2 spike protein appears to increase the amplitude of spontaneous $\mathrm{Ca}^{2+}$ signals. This is in line with previous reports that show that both TMEM16A and TMEM16F augment intracellular $\mathrm{Ca}^{2+}$ signals by increasing the filling of ER stores and augmenting $\mathrm{IP}_{3}$ receptor-induced $\mathrm{Ca}^{2+}$ release, thus amplifying $\mathrm{Ca}^{2+}$ signals activated by G-protein-coupled receptors ${ }^{24,25}$. 


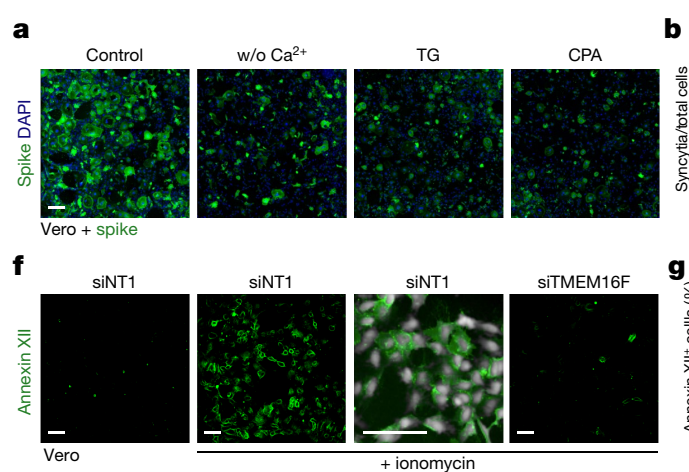

h
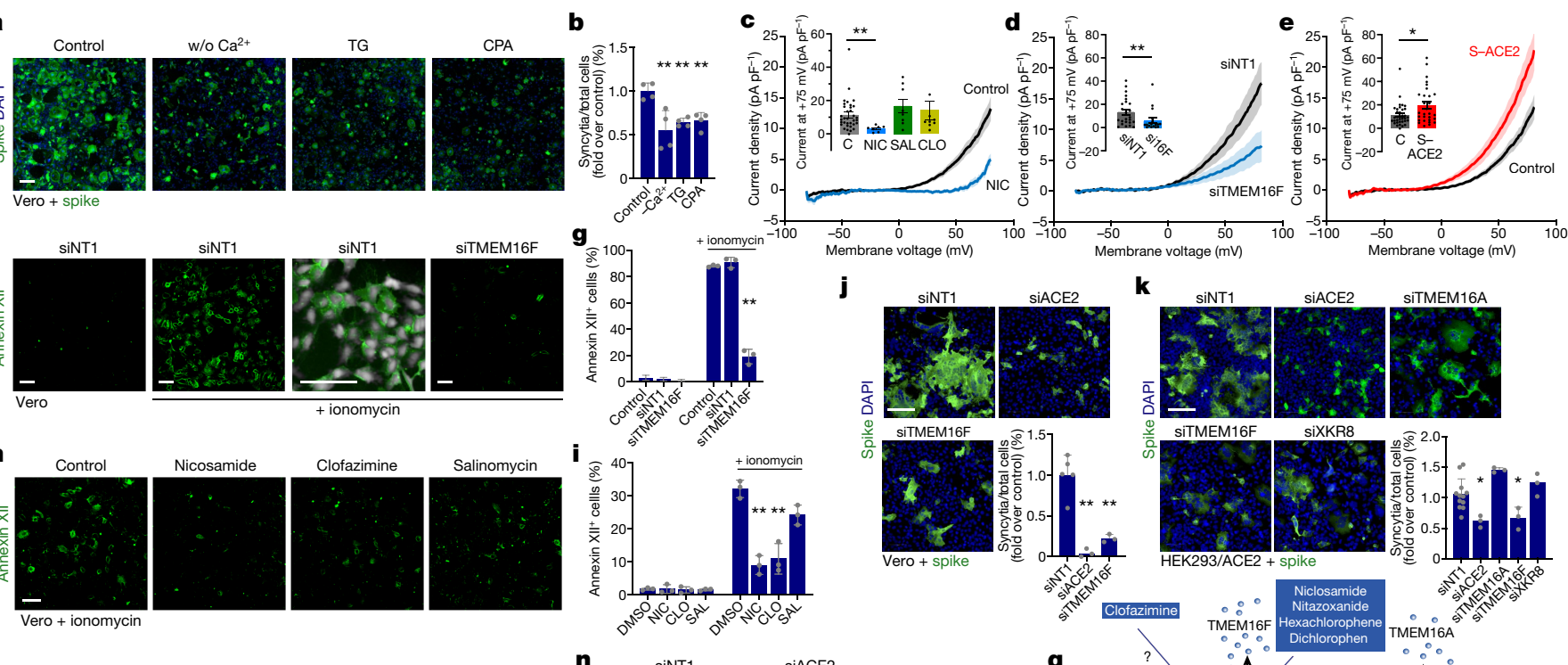

I
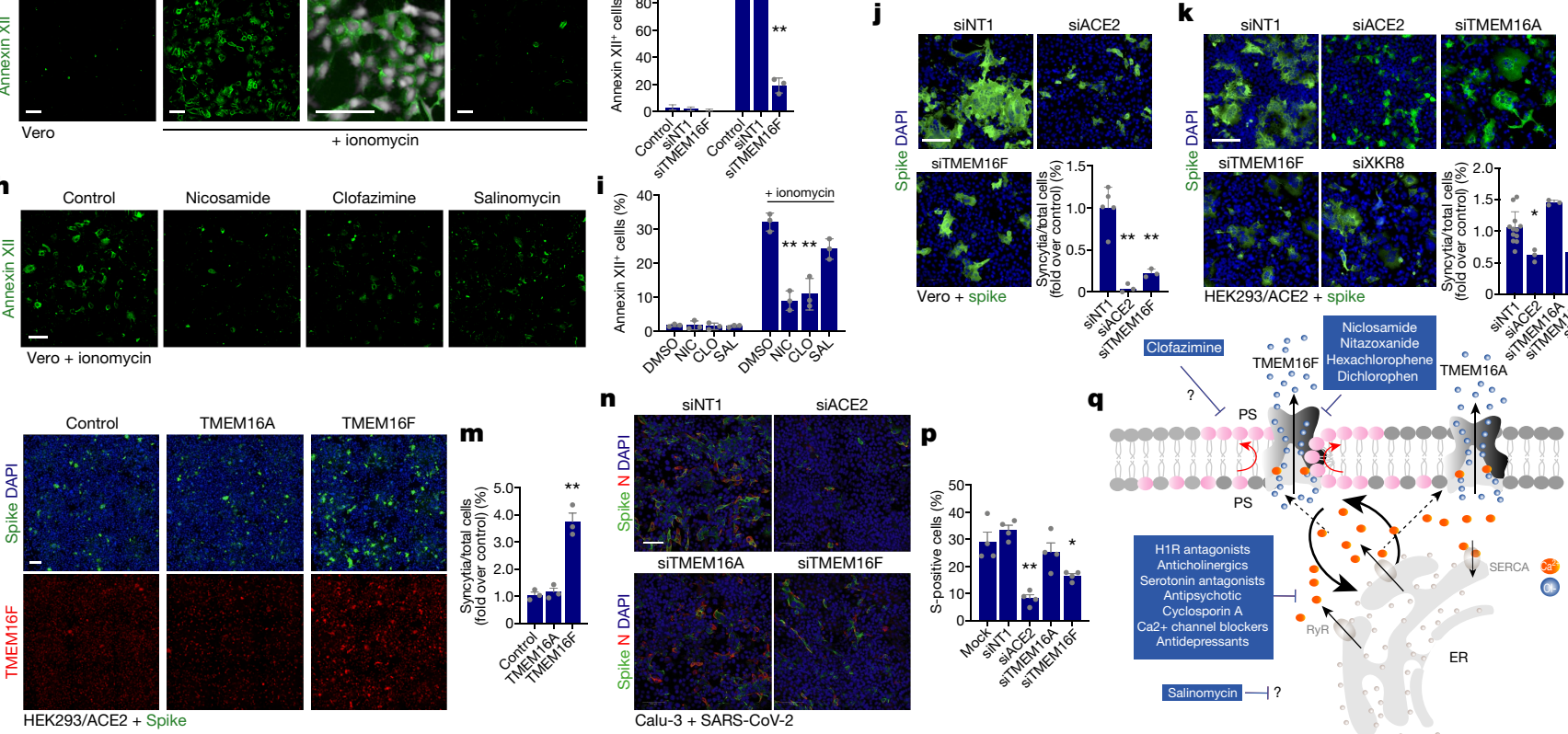

Fig. 3 | Calcium oscillations, chloride channel activity and requirement of TMEM16F protein for spike-mediated cell-cell fusion. $\mathbf{a}, \mathbf{b}$, Effect of $\mathrm{Ca}^{2+}$ depletion or treatment with the non-competitive SERCA inhibitors thapsigargin (TG) or cyclopiazonic acid (CPA) on syncytia (cell area $\geq 20,000 \mu \mathrm{m}^{2}$ ). Scale bar, $500 \mu \mathrm{m}$. Data are mean \pm s.d.; $n=4 .{ }^{* *} P<0.01$, one-way ANOVA with Bonferroni post hoc.c-e, Niclosamide-sensitive current is boosted by spike and ACE2 and inhibited by TMEM16F knockdown. Currents were measured using a voltage ramp in HEK 293 cells. In c, currents from control cells (black trace) were blocked by $2 \mu \mathrm{M}$ niclosamide (blue). Inset shows current density at $+75 \mathrm{mV}$ for control cells $(\mathrm{C}, n=34$ cells) and cells treated with niclosamide $(n=7)$, salinomycin $(n=8)$ and clofazimine $(n=9) .{ }^{* *} P<0.01$, Kruskal-Wallis, two-sided, with Dunn's post hoc. In d, cells transfected with control siRNA (siNT1) (black) ( $n=24)$ or TMEM16F siRNA (siTMEM16F) (blue) ( $n=17)$. Inset shows current density at $+75 \mathrm{mV} .{ }^{* *} P<0.01$, Mann-Whitney, two-sided. In e, cells transfected with eGFP control (C) (black) $(n=34$; as in c) or with eGFP, spike and ACE2 (S-ACE2) (red) $(n=29)$. Inset shows current density at $+75 \mathrm{mV}$. ${ }^{*} P<0.05$, Mann-Whitney, two-sided. Data are mean \pm s.e.m.

$\mathbf{f}, \mathbf{g}$, Phosphatidylserine externalization as measured by annexin XII staining after siRNA knockdown of TMEM16F $(n=3)$. Scale bars, $500 \mu \mathrm{m}$. Statistics as in

b. h, i, Phosphatidylserine externalization as measured by annexin XII after treatment with $100 \mathrm{nM}$ niclosamide, $500 \mathrm{nM}$ clofazimine or $500 \mathrm{nM}$ salinomycin $(n=3)$. Scale bar, $500 \mu \mathrm{m}$. Statistics as in $\mathbf{b} . \mathbf{j}, \mathbf{k}$, Inhibition of syncytia by siRNAs. Cells treated with the indicated siRNAs and, after $24 \mathrm{~h}$, transfected to express spike protein $(n=3)$. Scale bar, $200 \mu \mathrm{m}$. Data are mean \pm s.d. ${ }^{*} P<0.05,{ }^{* *} P<0.01$, one-way ANOVA with Dunnett post hoc. I, m, Overexpression of TMEM16F induces syncytia. HEK293 and ACE2 cells were co-transfected with spike and TMEM16A or TMEM16F $(n=3)$. Statistics as in $\mathbf{b}$. $\mathbf{n}, \mathbf{p}$, Inhibition of SARS-CoV- 2 infection by siRNAs. Calu- 3 cells were silenced for the indicated genes and, after $48 \mathrm{~h}$, infected with SARS-CoV-2 (MOI 0.5). One hour after infection, cells were washed and incubated with fresh medium. After $48 \mathrm{~h}$, cells were immunostained for spike and nucleocapsid $(\mathrm{N})$ proteins. Scale bar, $500 \mu \mathrm{m}$. Data are mean \pm s.e.m.; $n=4 .{ }^{* *} P<0.01$, one-way ANOVA with Dunnett's post hoc.q, Model showing the effect of drugs on syncytia and TMEM16F. Spike-expressing cells have increase $\mathrm{Ca}^{2+}$ (in orange) oscillations, leading to increased TMEM16F activity, which itself boosts $\mathrm{Ca}^{2+}$ levels. As a consequence, chloride (blue) secretion is increased, and phosphatidylserine (PS) (pink) is externalized. Drugs that block TMEM16F or blunting $\mathrm{Ca}^{2+}$ release inhibit spike-induced syncytia.

The involvement of TMEM16F in SARS-CoV-2 spike-induced syncytia is consistent with the previously proposed role of phosphatidylserine exposure in most other physiological cell fusion events. Macrophages fusing into inflammatory giant cells ${ }^{26}$ or to form bone-reabsorbing osteoclasts $^{27}$, myoblasts committed to fuse into myotubes ${ }^{28}$, cytotrophoblasts becoming syncytiotrophoblasts ${ }^{29}$ and, finally, sperm cells during egg fertilization ${ }^{30}$ all expose phosphatidylserine at the cell surface. In the cases of myoblasts and of placental development, TMEM16 $\mathrm{E}^{31}$ and $\mathrm{TMEM} 16 \mathrm{~F}^{32}$, respectively, were shown to specifically participate in this process.

From a mechanistic point of view, these finding are consistent with a model (Fig. 3q) by which the cells expressing SARS-CoV-2 spike protein have increased $\mathrm{Ca}^{2+}$ oscillations and increased activity of the plasma membrane TMEM16 channels, which leads to phosphatidylserine externalization and chloride secretion. Although the former event is

required for plasma membrane fusion, chloride secretion might have relevance in COVID-19 pathogenesis.

In addition to niclosamide, other drugs known to inhibit the TMEM16 family were also able to inhibit spike-induced syncytia in our assays, including nitazoxanide, hexachlorophene and dichlorophen. Gefitinib, which is known to block TMEM16A-activated EGFR on the plasma membrane $^{33}$, also inhibited spike-driven fusion. In addition, it seems likely that, similar to niclosamide and nitazoxanide ${ }^{22}$, other drugs that target TMEM16A (in particular, trifluoperazine ${ }^{34}$, serotonin reuptake inhibitors $^{35,36}$ and ivermectin ${ }^{37}$, all of which inhibited syncytia formation) might also inhibit TMEM16F. Thus, our screening for inhibition of syncytia seems to have disclosed a common mechanism for spike-dependent cell-cell fusion.

The activation of members of the TMEM16 family by SARS-CoV-2 spike protein might have specific relevance for COVID-19 pathogenesis, 
as it could participate in inflammation (TMEM16A promotes NK- $\mathrm{KB}$ activation and IL-6 secretion ${ }^{38}$ ), thrombosis (TMEM16F is essential for lipid scrambling in platelets during blood coagulation ${ }^{39,40}$ ), dysfunction of endothelial cells ${ }^{41}$ and alveolar oedema and diarrhoea through increased chloride secretion. As a consequence, the identified drugs are worth considering for COVID-19 therapy. In particular, niclosamide is a synthetic salicylanilide developed in the 1950 s as a molluscicide against snails ${ }^{42}$ and later approved in humans against tapeworm infection $^{43}$. Niclosamide has previously been reported to be active against various enveloped and non-enveloped viruses, including SARS-CoV- $2^{44}$. Although this drug has relatively low solubility, there is evidence of considerable absorption, with serum levels that can reach $1-20 \mu \mathrm{M}^{45,46}$. Together, our findings provide a mechanism and a rationale for repurposing of niclosamide to treat patients with COVID-19.

\section{Online content}

Any methods, additional references, Nature Research reporting summaries, source data, extended data, supplementary information, acknowledgements, peer review information; details of author contributions and competing interests; and statements of data and code availability are available at https://doi.org/10.1038/s41586-021-03491-6.

1. Levi, M., Thachil, J., Iba, T. \& Levy, J. H. Coagulation abnormalities and thrombosis in patients with COVID-19. Lancet Haematol. 7, e438-e440 (2020).

2. Goyal, P. et al. Clinical characteristics of Covid-19 in New York City. N. Engl. J. Med. 382 , 2372-2374 (2020).

3. Jose, R. J. \& Manuel, A. COVID-19 cytokine storm: the interplay between inflammation and coagulation Lancet Respir. Med 8, e46-e47 (2020).

4. Edler, C. et al. Dying with SARS-CoV-2 infection-an autopsy study of the first consecutive 80 cases in Hamburg, Germany. Int. J. Legal Med. 134, 1275-1284 (2020)

5. Hoffmann, M. et al. SARS-CoV-2 cell entry depends on ACE2 and TMPRSS2 and is blocked by a clinically proven protease inhibitor. Cell 181, 271-280 (2020).

6. Hoffmann, M., Hoffmann-Winkler, H. \& Pohlmann, S. Priming time: how cellular proteases arm coronavirus spike proteins. Activation Viruses Host Proteases https://doi. org/10.1007/978-3-319-75474-1_4 (2018).

7. Simmons, G. et al. Inhibitors of cathepsin $L$ prevent severe acute respiratory syndrome coronavirus entry. Proc. Natl Acad. Sci. USA 102, 11876-11881 (2005).

8. Glowacka, I. et al. Evidence that TMPRSS2 activates the severe acute respiratory syndrome coronavirus spike protein for membrane fusion and reduces viral control by the humoral immune response. J. Virol. 85, 4122-4134 (2011).

9. Matsuyama, S. et al. Efficient activation of the severe acute respiratory syndrome coronavirus spike protein by the transmembrane protease TMPRSS2. J. Virol. 84 12658-12664 (2010).

10. Shulla, A. et al. A transmembrane serine protease is linked to the severe acute respiratory syndrome coronavirus receptor and activates virus entry. J. Virol. 85, 873-882 (2011).

11. Millet, J. K. \& Whittaker, G. R. Host cell entry of Middle East respiratory syndrome coronavirus after two-step, furin-mediated activation of the spike protein. Proc. Natl Acad. Sci. USA 111, 15214-15219 (2014).

12. Burkard, C. et al. Coronavirus cell entry occurs through the endo-/lysosomal pathway in a proteolysis-dependent manner. PLoS Pathog. 10, e1004502 (2014).

13. Coutard, B. et al. The spike glycoprotein of the new coronavirus 2019-nCoV contains a furin-like cleavage site absent in CoV of the same clade. Antiviral Res. 176, 104742 (2020).

14. Hoffmann, M., Kleine-Weber, H. \& Pohlmann, S. A Multibasic cleavage site in the spike protein of SARS-CoV-2 is essential for infection of human lung cells. Mol. Cell 78, 779-784 (2020).

15. Bussani, R. et al. Persistence of viral RNA, pneumocyte syncytia and thrombosis are hallmarks of advanced COVID-19 pathology. Lancet EBioMedicine 61, 103104 (2020).

16. Marks, A. R. Intracellular calcium-release channels: regulators of cell life and death. Am. J. Physiol. 272, H597-H6O5 (1997).

17. Lang, F., Münzer, P., Gawaz, M. \& Borst, O. Regulation of STIM1/Orai1-dependent $\mathrm{Ca}^{2+}$ signalling in platelets. Thromb. Haemost. 110, 925-930 (2013).
18. Boselli, C., Barbone, M. S. \& Lucchelli, A. Older versus newer antidepressants: substance P or calcium antagonism? Can. J. Physiol. Pharmacol. 85, 1004-1011 (2007).

19. Berjukow, S. et al. Endogenous calcium channels in human embryonic kidney (HEK293) cells. Br. J. Pharmacol. 118, 748-754 (1996).

20. Chen, T. W. et al. Ultrasensitive fluorescent proteins for imaging neuronal activity. Nature 499, 295-300 (2013)

21. Thastrup, O., Cullen, P. J., Drøbak, B. K., Hanley, M. R. \& Dawson, A. P. Thapsigargin, a tumor promoter, discharges intracellular $\mathrm{Ca}^{2+}$ stores by specific inhibition of the endoplasmic reticulum $\mathrm{Ca}^{2+}$-ATPase. Proc. Natl Acad. Sci. USA 87, 2466-2470 (1990).

22. Miner, K. et al. Drug repurposing: the anthelmintics niclosamide and nitazoxanide are potent TMEM16A antagonists that fully bronchodilate airways. Front. Pharmacol. 10, 51 (2019).

23. Suzuki, J., Umeda, M., Sims, P. J. \& Nagata, S. Calcium-dependent phospholipid scrambling by TMEM16F. Nature $\mathbf{4 6 8}, \mathbf{8 3 4 - 8 3 8}(2010)$.

24. Jin, X. et al. Activation of the $\mathrm{Cl}^{-}$channel ANO1 by localized calcium signals in nociceptive sensory neurons requires coupling with the IP3 receptor. Sci. Signal. 6, ra73 (2013).

25. Cabrita, I. et al. Differential effects of anoctamins on intracellular calcium signals. FASEB J. 31, 2123-2134 (2017).

26. Helming, L. \& Gordon, S. Molecular mediators of macrophage fusion. Trends Cell Biol. 19 514-522 (2009)

27. Verma, S. K. et al. Cell-surface phosphatidylserine regulates osteoclast precursor fusion. J. Biol. Chem. 293, 254-270 (2018)

28. van den Eijnde, S. M. et al. Transient expression of phosphatidylserine at cell-cell contact areas is required for myotube formation. J. Cell Sci. 114, 3631-3642 (2001).

29. Lyden, T. W. Ng. A. K. \& Rote, N. S. Modulation of phosphatidylserine epitope expression by BeWo cells during forskolin treatment. Placenta 14, 177-186 (1993).

30. Rival, C. M. et al. Phosphatidylserine on viable sperm and phagocytic machinery in oocytes regulate mammalian fertilization. Nat. Commun. 10, 4456 (2019).

31. Whitlock, J. M., Yu, K., Cui, Y. Y. \& Hartzell, H. C. Anoctamin 5/TMEM16E facilitates muscle precursor cell fusion. J. Gen. Physiol. 150, 1498-1509 (2018).

32. Zhang, Y. et al. TMEM16F phospholipid scramblase mediates trophoblast fusion and placental development. Sci. Adv. 6, eaba0310 (2020).

33. Bill, A. et al. ANO1/TMEM16A interacts with EGFR and correlates with sensitivity to EGFR-targeting therapy in head and neck cancer. Oncotarget 6, 9173-9188 (2015).

34. Tian, Y. et al. Calmodulin-dependent activation of the epithelial calcium-dependent chloride channel TMEM16A. FASEB J. 25, 1058-1068 (2011).

35. Maertens, C., Wei, L., Voets, T., Droogmans, G. \& Nilius, B. Block by fluoxetine of volume-regulated anion channels. Br. J. Pharmacol. 126, 508-514 (1999).

36. Yang, Y. D. et al. TMEM16A confers receptor-activated calcium-dependent chloride conductance. Nature 455, 1210-1215 (2008).

37. Zhang, $\mathrm{X}$. et al. Inhibition of TMEM16A Ca ${ }^{2+}$-activated $\mathrm{Cl}^{-}$channels by avermectins is essential for their anticancer effects. Pharmacol. Res. 156, 104763 (2020).

38. Wang, Q. et al. TMEM16A Ca ${ }^{2+}$-activated $\mathrm{Cl}^{-}$channel inhibition ameliorates acute pancreatitis via the $\mathrm{IP}_{3} \mathrm{R} / \mathrm{Ca}^{2+} / \mathrm{NFKB} / \mathrm{IL}-6$ signaling pathway. J. Adv. Res. 23, 25-35 (2020)

39. Yang, H. et al. TMEM16F forms a $\mathrm{Ca}^{2+}$-activated cation channel required for lipid scrambling in platelets during blood coagulation. Cell 151, 111-122 (2012).

40. Baig, A. A. et al. TMEM16F-mediated platelet membrane phospholipid scrambling is critical for hemostasis and thrombosis but not thromboinflammation in mice-brief report. Arterioscler. Thromb. Vasc. Biol. 36, 2152-2157 (2016).

41. Ma, M. M. et al. TMEM16A contributes to endothelial dysfunction by facilitating Nox2 NADPH oxidase-derived reactive oxygen species generation in hypertension. Hypertension 69, 892-901 (2017).

42. Gonnert, R. \& Schraufstatter, E. A new molluscicide: molluscicide Bayer 73. Proc. Sixth Int. Congr. Trop. Med. Malaria, Lisbon, Sept. 5-13, 1958 2, 197-202 (1959).

43. Kappagoda, S., Singh, U. \& Blackburn, B. G. Antiparasitic therapy. Mayo Clin. Proc. 86, 561-583 (2011).

44. Jeon, S. et al. Identification of antiviral drug candidates against SARS-CoV-2 from FDA-approved drugs. Antimicrob. Agents Chemother. 64, e00819-20 (2020).

45. Andrews, P., Thyssen, J. \& Lorke, D. The biology and toxicology of molluscicides, Bayluscide. Pharmacol. Ther. 19, 245-295 (1982).

46. Burock, S. et al. Phase II trial to investigate the safety and efficacy of orally applied niclosamide in patients with metachronous or sychronous metastases of a colorectal cancer progressing after therapy: the NIKOLO trial. BMC Cancer 18, 297 (2018).

Publisher's note Springer Nature remains neutral with regard to jurisdictional claims in published maps and institutional affiliations.

(c) The Author(s), under exclusive licence to Springer Nature Limited 2021 


\section{Methods}

No statistical methods were used to predetermine sample size. The investigators were not blinded to allocation during experiments and outcome assessment, except where specified below. The experiments were not randomized.

\section{Patients}

Patients' lung samples are from post-mortem analysis of 6 patients who died of COVID-19 at the University Hospital in Trieste, Italy, after intensive care support. These are from a more extensive cohort of 41 consecutive patients, whoall died of COVID-19. Of these, 25 were male and 16 were female; the average age was 77 for men and 84 for women. During hospitalization, all patients scored positive for SARS-CoV-2 on nasopharyngeal swab and presented symptoms and imaging data indicative of interstitial pneumonia related to COVID-19 disease. Extensive characterization of these patients has previously been reported ${ }^{15}$. In these patients, dysmorphic and syncytial pneumocytes were present and abundant in the lungs of 20 patients (50\%), including all 6 patients requiring intensive care, and occasionally in an additional 16 patients (39\%). Use of these post-mortem samples for investigation was approved by the competent Joint Ethical Committee of the Regione Friuli Venezia Giulia, Italy (re. 0019072/P/GEN/ARCS).

\section{Cells}

Vero (WHO) clone 118 cells (ECACC 88020401 ) were cultured in DMEM (Life Technologies) with $1 \mathrm{gl}^{-1}$ glucose (Life Technologies) supplemented with $10 \%$ heat-inactivated fetal bovine serum (FBS) (Life Technologies) plus a final concentration of $100 \mathrm{IU} \mathrm{ml}^{-1}$ penicillin and $100 \mu \mathrm{g} \mathrm{ml}^{-1}$ streptomycin or without antibiotics where required for transfection. Cells were incubated at $37^{\circ} \mathrm{C}, 5 \% \mathrm{CO}_{2}$.

Vero E6 cells were provided by A. Davidson and D. Matthews. Cells were grown in DMEM (Gibco) containing 10\% FBS, $1 \%$ non-essential amino acids (Gibco) and $1 \%$ penicillin-streptomycin (Thermo Fisher Scientific). Cells were incubated at $37^{\circ} \mathrm{C}, 5 \% \mathrm{CO}_{2}$.

U-2 OS (U2OS; ATCC HTB-96), HEK293T (ATCC CRL-3216) and Calu-3 cells (ATCC HTB-55) were cultured in DMEM with $1 \mathrm{gl}^{-1}$ glucose (Life Technologies) supplemented with $10 \%$ FBS (Life Technologies) plus a final concentration of $100 \mathrm{IU} \mathrm{ml}^{-1}$ penicillin and $100 \mathrm{\mu g} \mathrm{ml}^{-1}$ streptomycin or without antibiotics where required for transfections.

The stable U2OS cell clone expressing mCherry was obtained by transduction with lentiviral particles for constitutive expression of mCherry (rLV.EF1.mCherry-9, Takara 0037VCT) at $10 \mathrm{MOI}$ with $4 \mu \mathrm{g} \mathrm{ml}^{-1}$ polybrene (Sigma-Aldrich TR-1003-G). The medium was replaced after $4 \mathrm{~h}$. Selection of the transduced cells was performed adding $1 \mu \mathrm{g} \mathrm{ml}^{-1}$ puromycin (InvivoGen ant-pr-1) starting $48 \mathrm{~h}$ after transduction. Expression of the transgene was verified by fluorescence microscopy.

Primary bronchial human airway epithelial cells were purchased from Epithelix and maintained in Mucilair cell culture medium (Epithelix).

All cell lines were negative for mycoplasma contamination. Cell lines were not authenticated.

\section{Antibodies}

Antibodies against the following proteins were used:TMEM16A (Abcam, ab64085), TMEM16F (Abcam ab234422 and Sigma-Aldrich HPA038958100UL), ACE2 (Abcam ab87436 and ab15348), V5 (Thermo Fisher Scientific R96025), V5-488 (Thermo Fisher Scientific 377500A488), mouse-HRP (Abcam ab6789), rabbit-HRP (Abcam ab205718), $\beta$-actin-HRP (Sigma-Aldrich A5316), napsin (Roche 760-4867), surfactant B (Thermo Fisher Scientific MS-704-P0), mouse-biotin (Vector Laboratories BA-9200), SARS-CoV-2 spike protein (GeneTex GTX632604), SARS-CoV-2 nucleocapsid antibody (Sino Biological 40143-R001).

\section{Cell fusion inhibition assay}

'Donor' U2OS cells were seeded in 10-cm Petri dishes ( 2 million cells per dish) to reach $70-80 \%$ confluency on the subsequent day. Transfection was performed using $10 \mu \mathrm{g}$ of either pEC117-Spike-V5 (expressing the V5-tagged Spike protein, codon optimized) or a control vector using $35 \mu \mathrm{l}$ of FuGENE HD Transfection Reagent (Promega E2311) in $500 \mu \mathrm{l}$ of Opti-MEM medium (Life Technologies). After overnight transfection, cells were loaded with $10 \mathrm{nM}$ Qtracker 525 Cell Labelling Kit (Invitrogen Q25041MP) in $1 \mathrm{ml}$ of medium for $1 \mathrm{~h}$ at $37^{\circ} \mathrm{C}$ in $5 \% \mathrm{CO}_{2}$. After extensive washes with PBS, cells were detached with Versene (Thermo Fisher Scientific 15040066). 'Acceptor' Vero cells were prepared as follows. Cells were seeded in $10-\mathrm{cm}$ Petri dishes (1.2 million cells per dish) the day before the assay. Cells were then loaded with $10 \mathrm{nM}$ Qtracker 800 Cell Labelling Kit (Invitrogen Q25071MP) in $1 \mathrm{ml}$ medium for $1 \mathrm{~h}$ at $37^{\circ} \mathrm{C}$ in $5 \%$ $\mathrm{CO}_{2}$. After extensive washes with PBS, cells were detached with $0.05 \%$ Trypsin-EDTA (Sigma-Aldrich T4049). Vero and U2OS cells were mixed at the final ratio of 5:4 and diluted at the final concentration of $20 \times 10^{3}$ cells $\mathrm{ml}^{-1}$ in DMEM with $1 \mathrm{gl}^{-1}$ glucose (Life Technologies) supplemented with $10 \%$ heat-inactivated FBS (Life Technologies). Diluted cells ( $50 \mu \mathrm{l}$ per well, 1,000 cells per well) were seeded in 12 384-well microplates (CellCarrierUltra 384, Perkin Elmer) using a Multidrop dispenser. Three hours after seeding, drugs from The Spectrum Collection, MS Discovery System (2,545 different drugs) and the Prestwick Chemical Library, Prestwick Chemical (1,280 drugs) were dispensed on top of cells at the final concentration of $10 \mu \mathrm{M}$ (1\% DMSO final). Twenty-four hours later, plates were washed in $50 \mu \mathrm{l}$ per well PBS and fixed in $40 \mu \mathrm{l} 4 \%$ paraformaldehyde (PFA) for $10 \mathrm{~min}$ at room temperature (RT). After fixation, cells were washed twice in $50 \mu \mathrm{l}$ per well PBS and permeabilized in 0.1\% Triton X-100 (Sigma-Aldrich 1086431000) for $10 \mathrm{~min}$ at room temperature. Cells were washed twice in $50 \mu \mathrm{l}$ per well of PBS and stained with HCS CellMask Blue (Thermo Fisher Scientific H32720) and Hoechst (H3570), according to the manufacturer's instructions.

Image acquisition was performed using an Operetta CLS high content screening microscope (Perkin Elmer) with a Zeiss $20 \times($ NA 0.80) objective. A total of 25 fields per well were imaged at three different wavelengths: (1) excitation 365-385 nm, emission 430-500 nm (nucleus and cytoplasm 'blue'); (2) excitation 460-490 nm, emission 500-550 nm (donor quantum dots 'green'); (3) excitation 615-645 nm, emission 655-750 nm (acceptor quantum dots 'red'). Images were subsequently analysed, using the Harmony software package (v.4.9; PerkinElmer). Images were first flatfield-corrected and nuclei were segmented using the 'Find Nuclei' analysis module (Harmony). The thresholds for image segmentation were adjusted according to the signal-to-background ratio. Splitting coefficient was set to avoid splitting of overlapping nuclei (fused cells). The cytoplasm area, stained by the HCS Cell Mask Blue, was defined using the 'Find Cytoplasm' analysis module (Harmony) and the number of either green or red spots was counted using the 'Find Spots' analysis module (Harmony). All the cells that had a nuclear area greater than four times the average area of a single nucleus and were simultaneously positive for at least two red and two green dots were considered as fused. Data were expressed as a percentage of fused cells by calculating the average number of fused cells normalized on the total number of cells per well.

\section{Syncytium inhibition assay}

Vero cells were seeded in $10-\mathrm{cm}$ Petri dishes ( 1.2 million cells per dish) to reach $70-80 \%$ confluency on the subsequent day. Transfection was performed using $10 \mu \mathrm{g}$ pEC117-Spike-V5 using $30 \mu \mathrm{l}$ and FuGENE HD Transfection Reagent (Promega E2311) in $500 \mu$ l of Opti-MEM medium (Life Technologies). Twelve hours after transfection, cells were detached, washed in PBS and diluted to the final concentration of $12 \times 10^{3} \mathrm{cells} \mathrm{ml}^{-2}$ in DMEM with $1 \mathrm{gl}^{-1}$ glucose (Life Technologies) supplemented with $10 \%$ heat-inactivated FBS (Life Technologies). Fifty microlitres of diluted cell suspension ( 600 cells per well) were seeded in 12384 -well microplates (CellCarrierUltra 384, Perkin Elmer) using a Multidrop dispenser. Three hours after seeding, drugs from The Spectrum Collection, MS Discovery System (2,545 different drugs) and the Prestwick Chemical Library, Prestwick Chemical (1,280 drugs) were dispensed on top of 
the cells at the final concentration of $10 \mu \mathrm{M}$ (1\% DMSO final). At $24 \mathrm{~h}$ after drug treatment, plates were washed in $50 \mu \mathrm{l}$ per well of PBS and fixed in $40 \mu \mathrm{l} \%$ PFA for $10 \mathrm{~min}$ at room temperature. After fixation, cells were processed for immunofluorescence using anti V5, Hoechst (H3570) and HCS CellMask Red (Thermo Fisher Scientific H32712), according to the manufacturer's instructions.

Image acquisition was performed using the Operetta CLS high content screening microscope (Perkin Elmer) with a Zeiss $20 \times$ (NA 0.80) objective. A total of 25 fields per well were imaged at three different wavelengths: (1) excitation 365-385 nm, emission 430-500 nm (nucleus 'blue'); (2) excitation 460-490 nm, emission $500-550 \mathrm{~nm}$ (spike protein 'green'); (3) excitation 615-645 nm emission 655-750 nm (HCS Cell Mask 'red'). Images were subsequently analysed, using the Harmony software (PerkinElmer). Images were first flatfield-corrected and nuclei were segmented using the 'Find Nuclei' analysis module (Harmony). The thresholds for image segmentation were adjusted according to the signal-to-background ratio. Splitting coefficient was set to avoid splitting of overlapping nuclei (fused cells). The cytoplasm area, stained by the HCS Cell Mask Red, was defined using the 'Find Cytoplasm' analysis module (Harmony) and the intensity of the green fluorescence was calculated using the 'Calculate Intensity Properties' module (Harmony). All the cells that had a nuclear area greater than five times the average area of a single nucleus and were simultaneously positive for green signal in the cytoplasm area were considered as fused. Data were expressed as a percentage of fused cells by calculating the average number of fused cells normalized on the total number of cells per well.

\section{Immunofluorescence}

After fixation in 4\% PFA for $10 \mathrm{~min}$ at room temperature, cells were washed two times in $50 \mu \mathrm{l}$ per well ( 384 well-plate) or $100 \mu \mathrm{l}$ per well (96-well plate) of PBS and then permeabilized in same volumes of $0.1 \%$ Triton X-100 (Sigma-Aldrich 1086431000) for 10 min at room temperature. Cells were then washed twice in PBS and blocked in $1 \%$ BSA for $1 \mathrm{~h}$ at room temperature. After blocking, the supernatant was removed, and cells were stained according to type of staining, as follows.

For V5 epitope staining, after blocking the supernatant was removed and $20 \mu \mathrm{l}$ per well ( 384 well-plate) or $40 \mu \mathrm{l}$ per well (96-well plate) of diluted (1:1,000 in 1\% BSA) V5 Tag Alexa Fluor 488 Monoclonal Antibody (Thermo Fisher Scientific 37-7500-A488) was added to each well and incubated at room temperature for $2 \mathrm{~h}$. Cells were then washed twice in PBS. Nuclear staining was performed by Hoechst 33342 according to the manufacturer's instruction.

For the staining of SARS-CoV-2 spike and nucleocapsid, and of cellular TMEM16F, after blocking the supernatant was removed and $40 \mu \mathrm{l}$ per well (96-well plate) diluted primary antibody (1:500 in 1\% BSA SARS-CoV-2 spike antibody [1A9], GeneTex GTX632604; TMEM16F antibody, Sigma-Aldrich HPA038958, 1:3,000 in BSA; and SARS-CoV-2 nucleocapsid antibody, Sino Biological 40143-R001) was added to each well and incubated overnight at $4{ }^{\circ} \mathrm{C}$. Cells were then washed twice in PBS, the supernatant was removed and same volumes of diluted (1:500 in $1 \%$ BSA) secondary antibody were added to each well and incubated $2 \mathrm{~h}$. Cells were then washed twice in PBS. Nuclear staining was performed by Hoechst 33342 according to the manufacturer's instructions.

Cytoplasmic staining was performed by HCS Cell Mask Deep Red Staining (Invitrogen H32721) or HCS Cell Mask Blue Staining (H32720) according to the manufacturer's instructions.

\section{Histology and immunohistochemistry}

Samples from COVID-19 autopsies were fixed in $10 \%$ formalin for at least $50 \mathrm{~h}$ and then embedded in paraffin. Four-micrometre sections were deparaffinized in xylene, rehydrated and processed for haematoxylineosin or immunohistochemical stainings. Antigen retrieval was performed in boiling sodium citrate solution $(0.01 \mathrm{M}, \mathrm{pH} 6.0)$ for $20 \mathrm{~min}$. Sections were allowed to cool down and permeabilized for $10 \mathrm{~min}$ in $1 \%$ Triton X-100 in PBS, followed by blocking in 2\% BSA (Roche) and overnight staining at $4{ }^{\circ} \mathrm{C}$ with the primary antibodies diluted in blocking solution. After endogenous peroxidase inhibition with $3 \% \mathrm{H}_{2} \mathrm{O}_{2}$, sections were incubated with appropriate biotin-conjugate secondary antibody for $1 \mathrm{~h}$ at room temperature. Following signal amplification with avidin-biotin-complex-HRP (Vectastain), DAB solution (Vector) was applied for 2-3 min. Haematoxylin (Bioptica) was further used to stain nuclei and Bluing reagent was used on Ventana automated stainings. Images were acquired using a Leica ICC50W light microscope.

\section{In situ hybridization}

In situ hybridization was performed using locked nucleic acid (LNA) probes for U6 snRNA ${ }^{47}$ and SARS-CoV-2 RNA, designed to target the sense strand of ORF1ab and spike regions of the viral genome. Scrambled sequences were used as control. Experiments were performed using a dedicated in situ hybridization kit for formalin-fixed paraffin-embedded (FFPE) tissues (Qiagen) according to the manufacturer's protocol. In brief, FFPE tissue slides were deparaffinized in xylene, treated with proteinase $\mathrm{K}\left(15 \mu \mathrm{g} \mathrm{ml}^{-1}\right)$ for $5 \mathrm{~min}$ at $37^{\circ} \mathrm{C}$ and incubated with either SARS-CoV-2 $(40 \mathrm{nM})$ or U6 probes $(2 \mathrm{nM})$ for $1 \mathrm{~h}$ at $54^{\circ} \mathrm{C}$ in a hybridizer. After washing with SSC buffer, the presence of SARS-CoV-2 RNA was detected using an anti-DIG alkaline phosphatase (AP) antibody (1:500) (Roche Diagnostics) supplemented with sheep serum (Jackson Immunoresearch) and bovine serum albumin (BSA). Hybridization was detected by adding NBT-BCIP substrate (Roche Diagnostics). Nuclei were counterstained with nuclear fast red.

\section{Plasmids}

The expression plasmid pEC117-Spike-V5 was generated as follows: the SARS-CoV-2 wild-type protein (NCBI accession number NC_045512.2, position 21563-25384) was codon-optimized and synthesized in two fragments of approximately $2 \mathrm{~kb}$ each as gBlock DNA fragments (IDT Integrated DNA Technologies) with the in-frame addition of the V5 tag at the $\mathrm{C}$ terminus, and then cloned into the pZac 2.1 backbone under the control of the cytomegalovirus (CMV) IE promoter. The construct DNA sequences were verified by Sanger sequencing. The following expression vectors were used: hTMEM16A (GenScript OHu26085D), hTMEM16F (GenScript OHu26351D), hACE2 (Addgene1786), pGCaMP6s (Addgene 40753), pMERS-CoV-S and pSARS-CoV-1-S (W. Barclay laboratory), pCMV-eGFP and pmCherry-NLS (the last two were obtained from L. Zentilin).

\section{siRNA transfection}

The siRNAs (Dharmacon siGENOMESMARTpools, four siRNAs per gene target) targeting $A C E 2$ (M-005755-00-0005), TMEM16A (also known as ANO1) (M-027200-00-0005), TMEM16B (ANO2) (M-016745-01-0005), TMEM16E (ANO5) (M-026787-00-0005), TMEM16F (ANO6) (M-00386701-0005) and $X K R 8$ (M-015745-01-0005) were dispensed onto the bottom of 96-well microplates (CellCarrierUltra 96, PerkinElmer); siRNA buffer and a non-targeting siRNA were used as controls. In brief, the transfection reagent (Lipofectamine RNAiMAX, Life Technologies) was diluted in Opti-MEM (Life Technologies) and added to each siRNA in the microplate array. Thirty minutes later, $6.5 \times 10^{3}$ Vero cells or $8 \times 10^{3}$ HEK293T cells were seeded in each well. All siRNAs were tested at different concentrations ranging from $6 \mathrm{nM}$ to $50 \mathrm{nM}$. Twenty-four hours after siRNA transfection, $100 \mathrm{ng}$ of either pEC117-Spike-V5 or pCMV-eGFP expression plasmid was transfected using a standard forward transfection protocol. In brief, pDNA was diluted in Opti-MEM (Life Technologies), mixed with the transfection reagent (FuGENE HD, Promega) using the following ratios: $1 \mu \mathrm{g}$ pDNA: $3 \mu$ l FugeneHD. The mix was incubated for $20 \mathrm{~min}$ at room temperature and added to the siRNA-transfected plates. After $24 \mathrm{~h}$, cells were fixed in $4 \%$ paraformaldehyde and processed for immunofluorescence. For gene silencing experiments, the indicated siRNAs were transfected into Vero or HEK cells using a standard reverse transfection protocol, at a final concentration of $25 \mathrm{nM}$. In brief, the transfection reagent (Lipofectamine RNAiMAX, Life Technologies) 
was diluted in Opti-MEM (Life Technologies) and added to the siRNAs arrayed in 12-well plates; 30 min later, approximately $1 \times 10^{5}-2 \times 10^{5}$ cells were seeded per well. After $48-72 \mathrm{~h}$, cells lysates were analysed by qPCR and/or western blotting, as detailed later.

\section{Phosphatidylserine externalization assay}

Vero cells were transfected with either pEC117-Spike-V5 and pmCherry-NLS or an empty pZac 2.1 vector, or reverse transfected with indicated siRNAs as described above. On the day of test, cells were seeded in 96-well microplates with a flat and clear bottom (CellCarrierUltra 96, Perkin Elmer) at a density of 6,500 cells per well for $2 \mathrm{~h}$. Cells were then treated with different drug concentrations for $1 \mathrm{~h}$. After one wash with medium without FBS at room temperature, cells were incubated with $100 \mu \mathrm{I} 1: 100$ annexin XII (pSIVA Abcam ab129817), with or without $5-10 \mu \mathrm{M}$ ionomycin. Cells were then immediately imaged by fluorescence microscopy using an Operetta CLS microscope mounting a $20 \times$ NA1.1 lens. Nine images per well were automatically acquired at different wavelengths: (1) excitation 460-490 nm, emission 500-550nm (annexin XII 'green'); (2) excitation 530-560, emission 570-650 nm (mCherry-NLS 'red'); (3) brightfield; (4) digital phase contrast.

\section{Calcium imaging}

Cells were seeded in $10-\mathrm{cm}$ Petri dishes ( 1.2 million cells per dish) to reach $70-80 \%$ confluency on the subsequent day and reverse transfected with indicate siRNAs. Co-transfection was performed using $5 \mu \mathrm{g}$ pGCaMP6s and $5 \mu \mathrm{g}$ either indicated CoV-S plasmids or an empty pZac 2.1 vector using $30 \mu \mathrm{l} \mathrm{FuGENE} \mathrm{HD} \mathrm{Transfection} \mathrm{Reagent} \mathrm{(Promega}$ E2311) in $500 \mu$ l of Opti-MEM medium (Life Technologies). Sixteen hours after transfection, cells were detached, washed in PBS and diluted to the final concentration of $6 \times 10^{4}$ cells per $\mathrm{ml}$ in DMEM with $1 \mathrm{~g} \mathrm{l}^{-1}$ glucose (Life Technologies) supplemented with $10 \%$ heat-inactivated FBS (Life Technologies). A total of 6,000 cells per well $(100 \mu \mathrm{l})$ were seeded in 96-well microplates with a flat and clear bottom (CellCarrierUltra 96, Perkin Elmer). For drug treatment experiments, cells were treated three hours after seeding with $1 \mu \mathrm{M}$ niclosamide (EP N0560000), $5 \mu \mathrm{M}$ clofazimine (EP Y0000313), $5 \mu \mathrm{M}$ salinomycin (Sigma S4526-5) or $1 \%$ DMSO. For calcium-depletion assays, cells were kept in calcium-free medium or treated with either $10 \mu \mathrm{M}$ cyclopiazonic acid (Tocris 1235), $500 \mathrm{nM}$ thapsigargin (Tocris 1138 ) or $0.1 \%$ DMSO.

Image acquisition was performed using the Operetta CLS high content screening microscope (Perkin Elmer) with a Zeiss $20 \times$ (NA 0.80) objective at $37^{\circ} \mathrm{C}$ and $5 \% \mathrm{CO}_{2}$. A total of three fields per well were imaged every 2 min at excitation $460-490 \mathrm{~nm}$, emission $500-550 \mathrm{~nm}$ (GCaMP6s sensor 'Green'). Images were subsequently analysed with the ImageJ software. For each frame, fluorescence intensity $(F)$ was subtracted from the same frame in the preceding acquisition to remove the background signal and to calculate $\Delta F / F_{0}$ index, in which $F_{0}$ is the median baseline fluorescence and $\Delta F=F-F_{0}$. For intensity analysis, more than $12180-\mu \mathrm{m}^{2}$ regions of interest (ROIs) per condition were considered, compiling a total of at least 50 GCaMP6s-positive cells per condition. For each ROI, positive $\Delta F$ values (that is, increase) were taken into account with the BAR script 'Find peaks'. Among these, values outside 1.5 times the interquartile range above the upper quartile were considered as ‘spikes'. Single-cell spike frequency was then counted for the whole observation period.

\section{RNA extraction and qPCR}

Total mRNA was isolated from HEK293T or Vero cells 48-72 h after siRNA transfection using a standard Trizol RNA extraction protocol. The RNA obtained $(0.5-1 \mu \mathrm{g})$ was reverse-transcribed using MLV-RT (Invitrogen) with random hexameric primers $(10 \mu \mathrm{M})$ in a $20-\mu$ l reaction following the manufacturer's instructions. Quantification of the gene expression of TMEM16A (Hs00216121_m1), TMEM16B (Hs00220570_m1), TMEM16E (Hs01381106_m1) and TMEM16F (Hs03805835_m1) was performed by quantitative PCR (qPCR) using Taqman probes and primers for SYBR Green analysis. Expression of the housekeeping gene GAPDH (Hs02786624_g1) was used for normalization.

Amplifications were performed using a QuantStudio3 machine using TaqMan Gene Expression Master Mix (Applied Biosystems 4369016). The qPCR profile was programmed with a standard protocol, according to the manufacturer's instructions. See Supplementary Table 3 for the primer sequences used in the qPCR assays.

\section{Western blotting}

After siRNA transfections for 48-72 h, HEK293 cells were collected and homogenized in RIPA lysis buffer (20 mM Tris-HCl, pH 7.4, 1 mM EDTA, $150 \mathrm{mM} \mathrm{NaCl}, 0.5 \%$ Nonidet P-40, $0.1 \%$ SDS, $0.5 \%$ sodium deoxycholate supplemented with protease inhibitors (Roche)) for 10 min at $4{ }^{\circ} \mathrm{C}$ and sonicated by using Bioruptor (Diagenode) for $30 \mathrm{~min}$. Equal amounts of total cellular proteins $(15-20 \mu g)$, as measured with the Bradford reagent (Biorad), were resolved by electrophoresis in $4-20 \%$ gradient polyacrylamide gels (Mini-PROTEAN, Biorad) and transferred to nitrocellulose/PVDF membranes (GE Healthcare). Membranes were blocked at room temperature for $60 \mathrm{~min}$ with PBST (PBS + 0.1\% Tween20) with $5 \%$ skim milk powder (Cell Signaling, 9999). Blots were then incubated $\left(4^{\circ} \mathrm{C}\right.$, overnight) with primary antibodies against ACE2 (diluted 1:1,000), TMEM16F (1:1,000), $\beta$-actin (diluted 1:5,000), V5 (diluted 1:5,000) or TMEM16F (diluted 1:500), TMEM16A (diluted 1:500) and TMEM16B (diluted 1:1,000). Blots were washed three times ( $5 \mathrm{~min}$ each) with PBST. For standard western blotting detection, blots were incubated with either anti-rabbit HRP-conjugated antibody $(1: 5,000)$ or anti-mouse HRP-conjugated antibody $(1: 10,000)$ for $1 \mathrm{~h}$ at room temperature. After washing three times at room temperature with PBST (10 min each), blots were developed with ECL (Amersham).

\section{Electrophysiology}

Whole-cell patch clamp recordings were carried out on HEK293 cells grown on glass cover slips coated with poly-L-lysine. After plating, cells were transfected the following day with either eGFP or a combination of eGFP, spike protein and ACE2. Recordings were typically carried out 12-36 $\mathrm{h}$ after transfection. TMEM16F knockdown experiments were carried out as above by transfecting HEK293 cells with either a control siRNA (NT1) or an siRNA targeting TMEM16F. Delivery of siRNA was done by plating $500 \times 10^{3} \mathrm{HEK} 293$ cells together with $12.5 \mathrm{nM}$ siRNA per well of a 12-well plate. Twenty-four hours after siRNA transfections, cells were transfected with a pCMV-eGFP expression plasmid as described. Six hours after transfection, cells were plated onto $18 \mathrm{~mm}$ diameter glass cover slips coated with poly-L-lysine seeded at $10 \times 10^{3}$ cells per well, and recorded 12 to $36 \mathrm{~h}$ after plating.

Whole-cell recordings were performed in an $\mathrm{HBS}$ extracellular solution ( $\mathrm{pH} \mathrm{7.3,} 315 \mathrm{mOsm}$ ) that contained (in $\mathrm{mM}$ ): $139 \mathrm{NaCl}, 2.5 \mathrm{KCl}$, $10 \mathrm{HEPES}, 10$ glucose, $1.3 \mathrm{MgCl}_{2}$ and $2 \mathrm{CaCl}_{2}$. Patching electrodes were made from thick-walled borosilicate glass (outer diameter: $1.5 \mathrm{~mm}$, inner diameter $0.86 \mathrm{um}$, Sutter Instruments) obtaining a resistance between 3 and $4 \mathrm{M} \Omega$ and filled with an intracellular solution containing (in $\mathrm{mM}$ ): $130 \mathrm{CsCl}, 10 \mathrm{HEPES}, 10 \mathrm{EGTA}, 1 \mathrm{MgATP}, 1 \mathrm{MgCl}_{2}$ and free calcium adjusted to $28 \mu \mathrm{M}$ using $\mathrm{CaCl}_{2}$ according to calculations using MAXchelator Ca-Mg-ATP-EGTA Calculator v.1.0 software. Solution was adjusted to a pH of 7.4 using $\mathrm{CsOH}$ and osmolarity to $290 \mathrm{mOsm}$. Recordings were obtained with a Multiclamp 700B amplifier (Molecular Devices) and digitized with the Digidata 1440A digitizer (Molecular Devices). Data were acquired with the software Clampex v.10.3.1.5 (Molecular Devices) and Axon Multiclamp 700B Commander Software (Molecular Devices). Signals were sampled at $5 \mathrm{kHz}$ and filtered at $2.5 \mathrm{kHz}$. Pipette offsets were nulled before seal formation and pipette capacitance was compensated in the cell-attached configuration once a giga-seal was obtained. We used responses to hyperpolarizing and depolarizing steps to estimate the series resistance $\left(R_{\mathrm{s}}\right)$ of the recording, the membrane resistance $\left(R_{\mathrm{m}}\right.$; from the steady holding current at the new voltage) and membrane capacitance ( $C_{\mathrm{m}}$; from the area under the exponentially 
decaying current from peak to holding). Recordings were excluded if access resistance exceeded $15 \mathrm{M} \Omega$ and if input resistance was lower than $150 \mathrm{M} \Omega$. All recordings were carried out at room temperature.

Our strategy was to target cells that were mononuclear (cells that had not yet fused), as we found that we were unable to obtain stable recordings from large syncytia. Although it is possible that some of the recordings of the spike-expressing cells include early stage syncytia, they are unlikely to contain more than 2 nuclei. In fact, the mean membrane capacitance, an indirect measure of cell size, was not significantly different between the different experimental groups. Nevertheless, to avoid any issues with cell size, all currents were expressed as current density. Cells were held at $0 \mathrm{mV}$ and ramps consisted of either a short $20 \mathrm{~ms}$ step to $-80 \mathrm{mV}$ followed by $500 \mathrm{~ms}$ ramp from -80 to $+80 \mathrm{mV}$ or a longer $300 \mathrm{~ms}$ step to $-80 \mathrm{mV}$ followed by $500 \mathrm{~ms}$ ramp from -80 to $+80 \mathrm{mV}$. Data were pooled from both as there was no significant difference in the current responses. To remove the leak current from the ramp protocols, a line was fit to the current measured from -80 to $-20 \mathrm{mV}$ and subtracted from the entire curve. The resulting ramps showed clearly identifiable outwardly rectifying currents that reversed at $0 \mathrm{mV}$. Analysis was carried out using custom written routines in Matlab v. R2019a and on Prism v.9.0.1 (GraphPad).

\section{SARS-CoV-2 infection}

SARS-CoV-2/England/IC19/2020 (IC19), isolated on Caco2 cells from a clinical sample collected from a patient admitted to St Mary's Hospital in London (UK) was used for the cell protection assays. Cell survival after viral infection was measured by fixing the cells in $4 \%$ PFA, followed by quantification, using high-content microscopy, of the total cell area per well using DPC (Digital Phase Contrast) imaging.

SARS-CoV-2 strain England 02/2020/407073 used to study drug antiviral effect was provided by Public Health England (courtesy of M.Zambon and $\mathrm{H}$.McGregor $\left.{ }^{48,49}\right)$. For the drug inhibition assays, drugs were diluted in DMSO and added to 96-well plates of Vero E6 cells for $2 \mathrm{~h}$. Virus was added at an MOI 0.05 for $1 \mathrm{~h}$, the cells washed with PBS and then cultured in fresh drug-containing medium for a further $48 \mathrm{~h}$. Virus production in the culture supernatants was quantified by plaque assay using Vero E6 cells. The $\mathrm{IC}_{50}$ value was defined as the drug concentration at which there was a $50 \%$ decrease in the titre of supernatant virus. Data were analysed using Prism 8.0 (GraphPad), and $\mathrm{IC}_{50}$ values were calculated by nonlinear regression analysis using the dose-response (variable slope) equation.

\section{Reporting summary}

Further information on research design is available in the Nature Research Reporting Summary linked to this paper.

\section{Data availability}

There are no restrictions on data availability. CAS numbers for the investigated drugs are reported in the Article. All data are reported in the Article or the Supplementary Information.

47. Gabisonia, K. et al. MicroRNA therapy stimulates uncontrolled cardiac repair after myocardial infarction in pigs. Nature 569, 418-422 (2019).

48. Seow, J. et al. Longitudinal observation and decline of neutralizing antibody responses in the three months following SARS-CoV-2 infection in humans. Nat. Microbiol. 5, 1598-1607 (2020).

49. Carter, M. J. et al. Peripheral immunophenotypes in children with multisystem inflammatory syndrome associated with SARS-CoV-2 infection. Nat. Med. 26, 1701-1707 (2020).

Acknowledgements We thank S. Neil, A. Cave, G. Giacca, A. Ivetic and all the other members of the Giacca laboratory who contributed from home during the lockdown period for comments. We acknowledge the generosity of N. Leblanc, K. M. Hoque, M. Hayashi and lain Greenwood for their gift of reagents and thank M. Guiomar Oliveira for assisting in preparing the cell cultures for electrophysiology. This work was supported by grants from the King's College London King's Together programme (to M.G. and M.H.M.); British Heart Foundation (BHF) Programme Grant RG/19/11/34633 (M.G.); King's College London BHF Centre of Research Excellence grant RE/18/2/34213 (to A.M.S. and M.G.); European Research Council (ERC) Advanced Grant 787971 'CuRE' (to M.G.); Wellcome Trust Investigator Awards (215508/Z/19/Z to J.B. and 106223/Z/14/Z to M.H.M.), BBSRC project grant BB/S000526/1 (J.B.), Huo Family Foundation (M.H.M.), National Institute of Allergy and Infectious Diseases (U54AI150472 and R01AI076119, M.H.M.) and National Institute for Health Research Biomedical Research Centre at Guy's \& St Thomas' NHS Foundation Trust and King's College London (IS-BRC-1215-20006, A.M.S., M.H.M. and M.G.).

Author contributions L.B. performed the HTS screenings; H.A., I.S. and L.B. performed most cellular biology studies (phosphatidylserine externalization, effect of plasmid overexpression and RNAi studies). H.A. performed the immunoblottings. I.S. performed the time-lapse imaging studies. E.C. performed expression vector cloning and analysis of spike intracellular trafficking. G.N. and J.B. performed the electrophysiology study. D.G., R.P. and W.S.B. performed studies on the effect of drugs on the protectin of Vero and Calu-3 cells from SARS-CoV-2; J.M.J.-G., A.M.O.-P. and M.H.M. performed antiviral activity experiments against SARS-CoV-2 and RNAi studies on Vero and Calu-3 cells; R.B. performed autopsies and histology on patients' samples; A.C. provided consultancy on clinical drug mechanism of action; G.R. performed investigations on the effect of spike protein on cellular pathways; C.C. performed immunohistochemistry on patients' samples; E.S. performed in situ RNA hybridization on patients' samples; D.A. provided consultancy and reagents for chloride channel studies; A.M.S. provided advice on the design and the clinical aspects of the study. M.G. conceived and coordinated the study. I.S., E.C., G.N. and D.G. contributed equally.

Competing interests King's College London has filed a patent application on the methods used to detect SARS-CoV-2 spike protein-induced syncytia as described in this Article.

Additional information

Supplementary information The online version contains supplementary material available at https://doi.org/10.1038/s41586-021-03491-6.

Correspondence and requests for materials should be addressed to M.G.

Peer review information Nature thanks Lily Jan and the other, anonymous, reviewer(s) for their contribution to the peer review of this work.

Reprints and permissions information is available at http://www.nature.com/reprints. 


\section{Article}

a
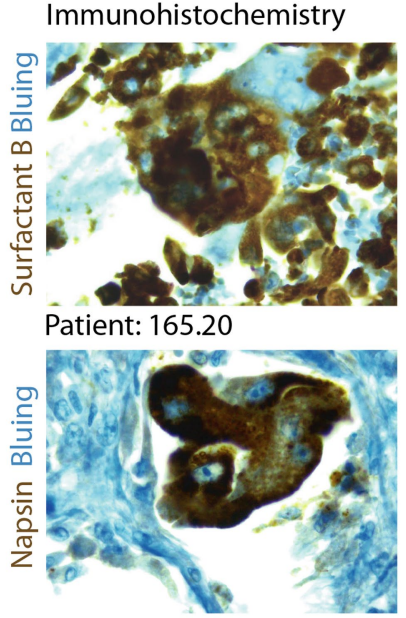

Patient: 308.20

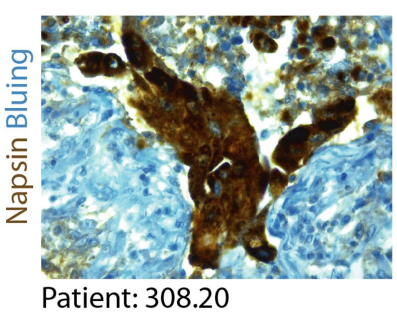

C
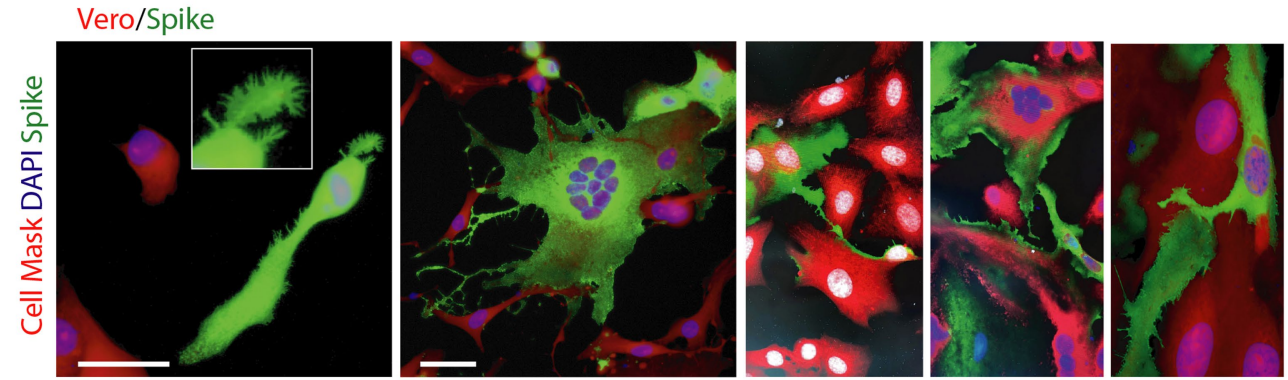

d
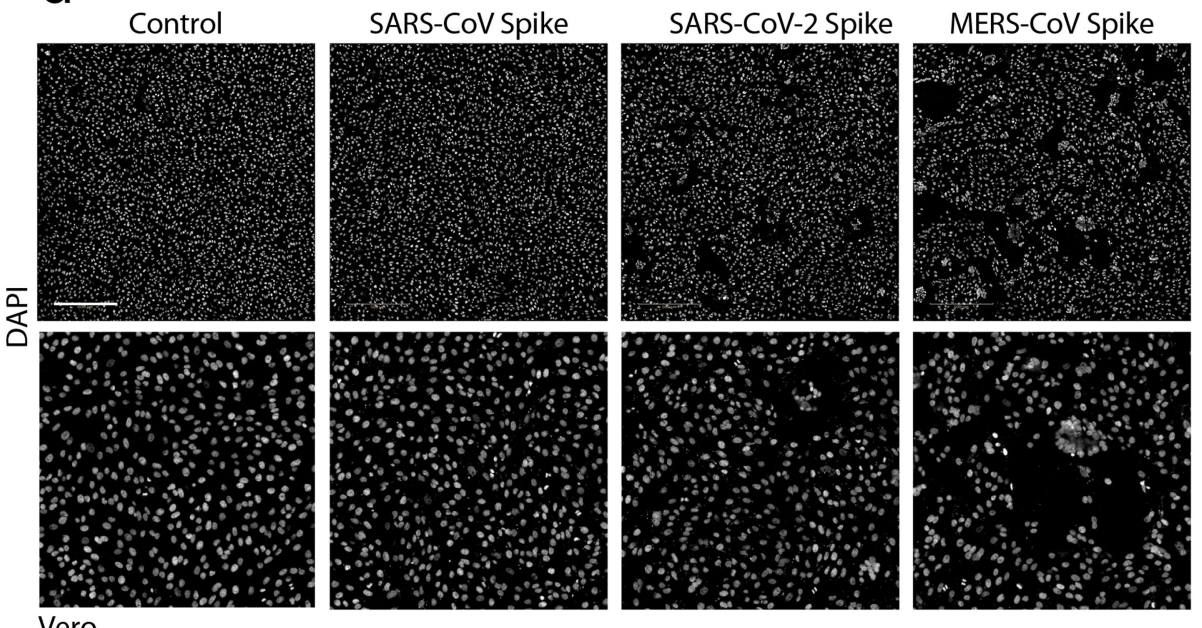

e

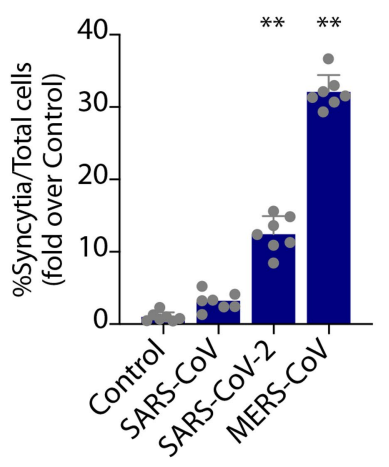

Extended Data Fig. 1 |See next page for caption. 
Extended Data Fig. 1 | Syncytia induced by coronavirus spike proteins. a, Syncytial pneumocytes in the lungs of COVID-19 patients.

Immunohistochemistry using the indicated antibodies. Original magnification, $\times 40$. Further information on the patient cohort has previously been described ${ }^{15}$.b. In situ hybridization using two LNA-modified RNA probes for the SARS-CoV-2 genome (top four panels) and

immunohistochemistry with an anti-spike antibody. Lung samples from individuals who died in 2018 for other causes served as negative controls for this analysis, and a positive control was hybridization with a probe for the ubiquitous $U 6$ RNA, as previously described ${ }^{47}$, which showed nuclear localization in all cells. Scale bar, $50 \mu \mathrm{m}$. The in situ hybridization technique was previously described ${ }^{15}$.c. Cytological alterations induced by the spike protein. Vero cells were transfected with a spike-expressing plasmid and cultured for $12 \mathrm{~h}$; spike protein was then visualized by immunofluorescence and cell body was stained using HCS CellMask DeepRed.Spike-positive cells show marked morphological alterations, including presence of numerous filopodia (inset in the left panel) and membrane protrusions contacting the plasma membrane of neighbouring cells. Scale bar, $50 \mu \mathrm{m}$. d, e, Syncytia induced by other coronavirus spike proteins. Vero cells were transfected to express the spike protein of MERS-CoV, SARS-CoV or SARS-CoV-2. After $24 \mathrm{~h}$, cells were immunostained for nuclei (white). Representative images are in $\mathbf{d}$, and quantification is in e. Data are mean \pm s.e.m.; $n=4 .{ }^{* *} P<0.01$, one-way ANOVA with Bonferroni correction. 


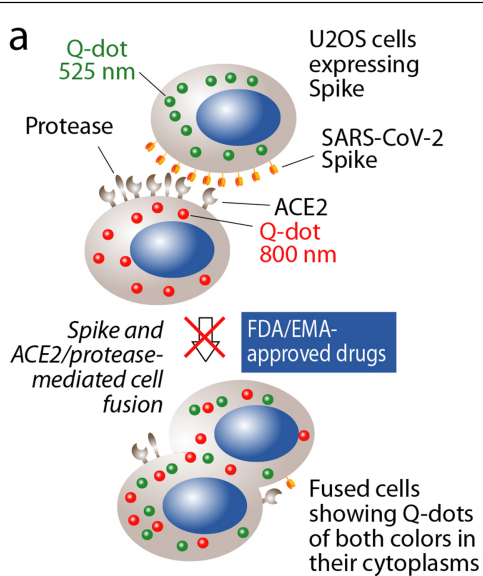

C
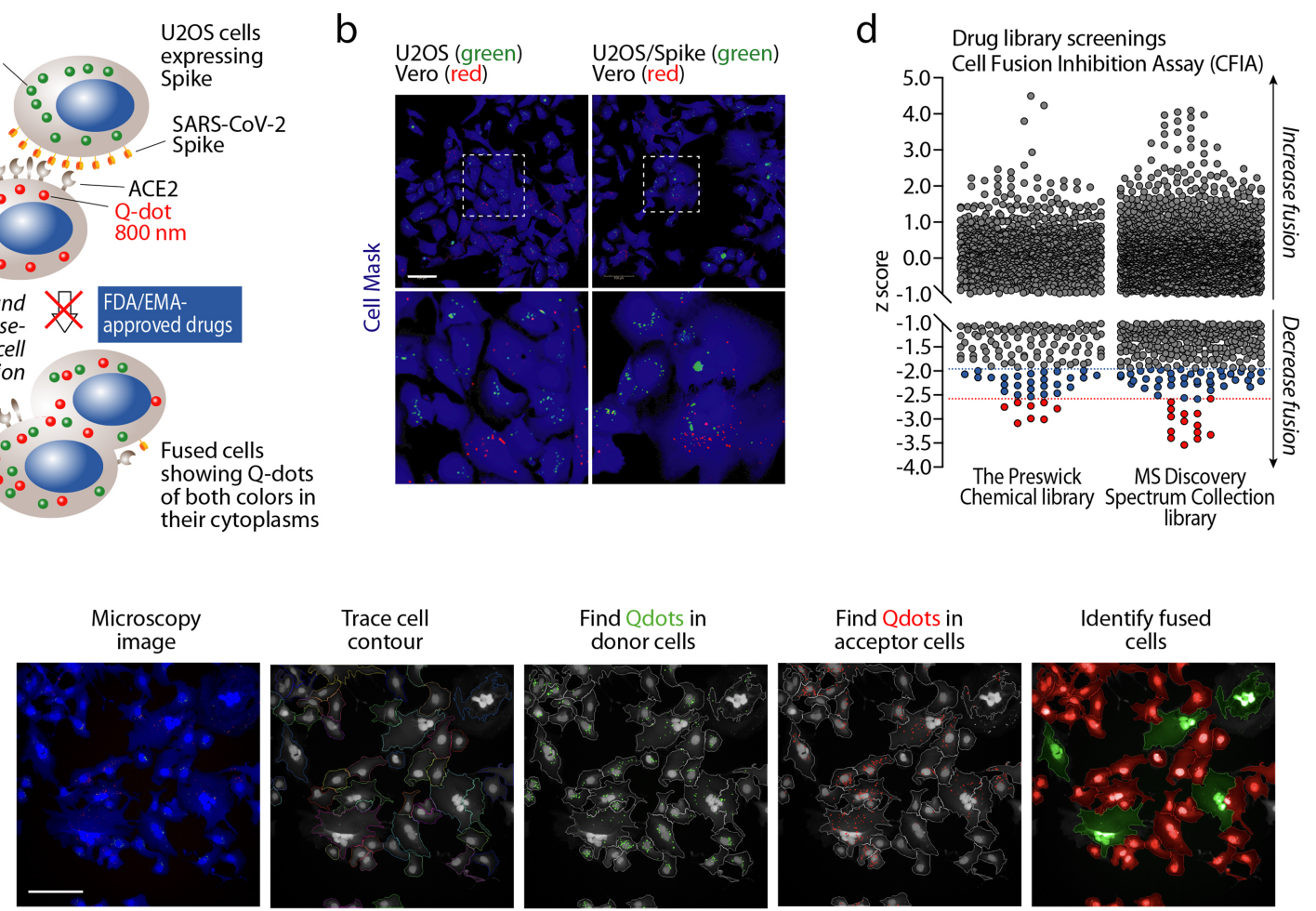

e
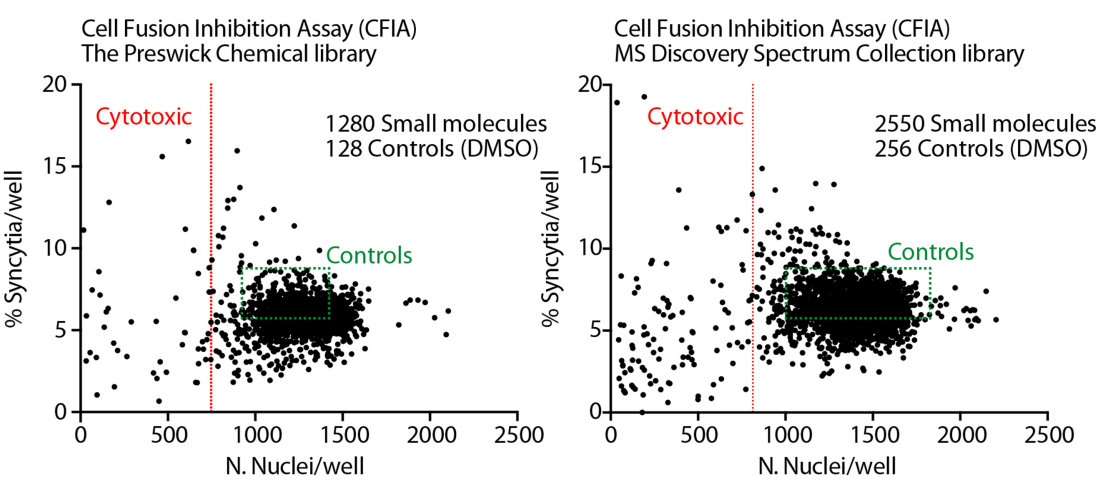

$f$
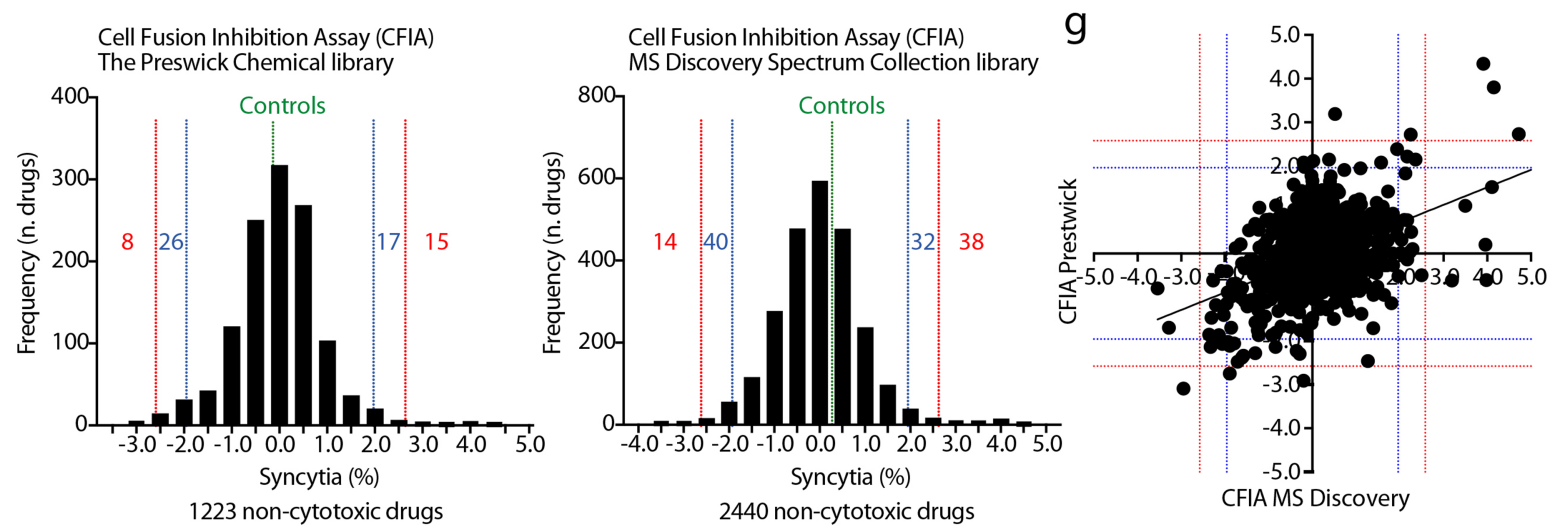

CFIA MS Discovery

Extended Data Fig. 2 |See next page for caption. 
Extended Data Fig. 2 | Cell fusion inhibition assay. a, Scheme of cell fusion inhibition assay. The assay is based on the co-culture, for $12 \mathrm{~h}$, of Vero cells with U2OS cells transiently transfected to express spike protein. To permit quantitative assessment of cell fusion by high-content microscopy, the spike 'donor' U2OS cells are loaded with quantum dots (Q-dots) emitting at $525 \mathrm{~nm}$ (green) whereas the 'acceptor' Vero cells with Q-dots emitting at $800 \mathrm{~nm}$ (red). Screenings were performed in 384-well plates by co-plating Q-dot loaded 'donor' and 'acceptor' cells, followed by drug treatment at $10 \mu \mathrm{M}$ standard concentration. After $24 \mathrm{~h}$, cells were fixed and processed by high-content microscopy. Multiple control wells with $1 \%$ DMSO and no drugs were included in each plate. b, Fluorescent images of co-cultured U2OS (green Q-dots) and Vero (red Q-dots) cells. Cells are stained with HCS CellMask Blue; fused cells (heterokaryons) are identified as cells having more than two nuclei and containing both green and red Q-dots in their cytoplasm. Thus, the CFIA assay scores for the effect of drugs on the fusion of heterologous cells and detects inhibitors that block fusion of as few as two cells. The assay has a more than fivefold dynamic range. Scale bar, $100 \mu \mathrm{m} \mathrm{c}$, CFIA image high content analysis pipeline. Images were analysed using the Harmony software (PerkinElmer). The cytoplasmic area, stained by the HCS Cell Mask Blue, was defined using the 'Find Cytoplasm' analysis module (Harmony) and the number of either green or red spots was counted using the 'Find Spots' analysis module (Harmony). All the cells that scored a nuclear area greater than five times the average area of a single nucleus and were simultaneously positive for at least two red and two green dots were considered as fused (highlighted in green). Data were expressed as a percentage of fused cells. $d$, Cumulative results of CFIA screening of FDA/EMA-approved drug libraries. We screened two FDA/EMAapproved drug libraries, The Spectrum Collection, MS Discovery System, and the Prestwick Chemical Library, Prestwick Chemical; 2,545 and 1,280 individual small molecules, respectively. The graph shows the cumulative results of the two screenings. The percentage of syncytia normalized on total cells is plotted as a $z$ score. Compounds with a $z$-score $\leq-2.58$ (red dotted line, $0.005 \%$ tail of the distribution) are shown in red, those between $\leq-1.96(0.025 \%$ tail, blue dotted line) and -2.58 are in blue. In the Prestwick collection, 34 drugs inhibited S-mediated fusion with a $z$ score $<-1.96$, of which 8 with a $z$ score of $<-2.58$. In the MS Discovery Spectrum collection, 54 drugs performed at a $z$ score $<-1.96$ of which 14 with a $z$ score of $<-2.58$. All untreated controls for both libraries had a $z$ score in the \pm 0.40 range. e. Analytic evaluation of CFIA results. A correlation chart between the percentage of syncytia per well and the total number of cells per well is shown for the two screened drug libraries. Drugs showing a total number of cells at $\geq 2$ s.d. lower than the average of all drugs (red dotted line) considered toxic and not included in the subsequent analysis. Distribution of control wells ( $1 \%$ DMSO) is shown by a green box.f, Distribution frequency of the percentage of syncytia plotted as the number of drugs versus the $z$ score of the percentage of syncytia per well; toxic cells were excluded as in e. Blue dotted lines are at $z$ scores \pm 1.96 and red dotted lines at $z$ scores \pm 2.56 . The numbers of drugs are shown. $\mathrm{g}$, Correlation chart for the common drugs between the two libraries. Data are plotted as the $z$ score of the percentage of syncytia per well. Blue and red lines are as above. 
a Syncytium Inhibition Assay (SIA)

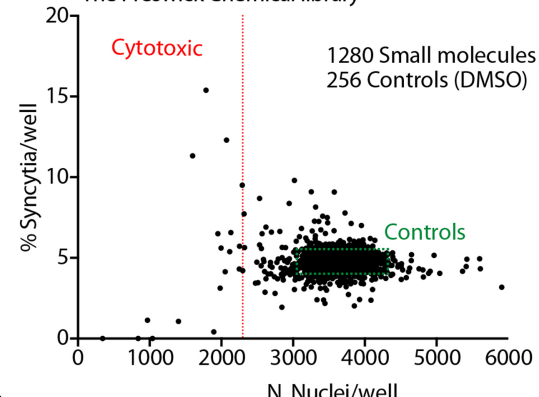

b

N. Nuclei/well

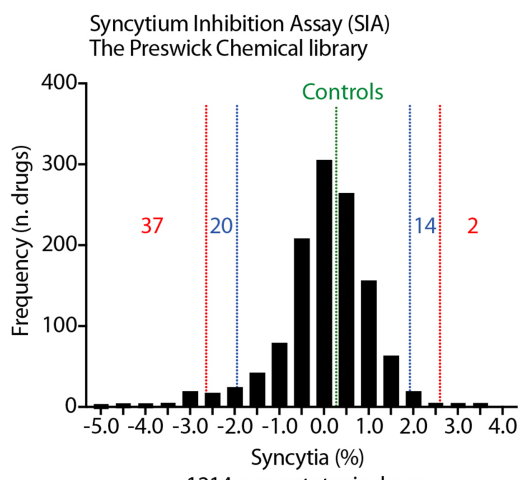

1214 non-cytotoxic drugs

d
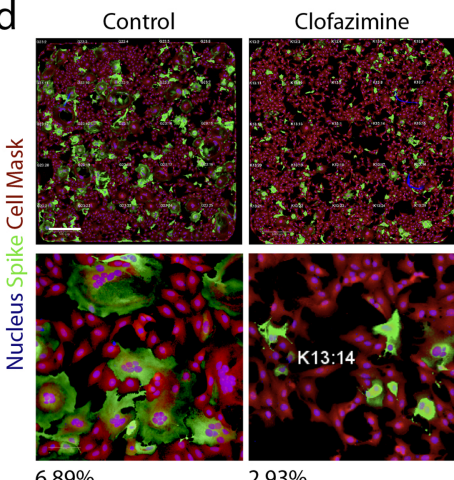

$2.93 \%$

e

Vero cells

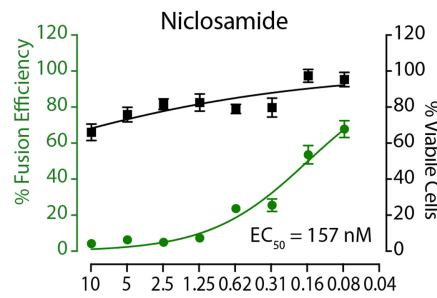

HEK293/ACE2 cells

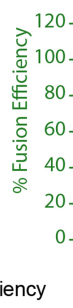

- Viability

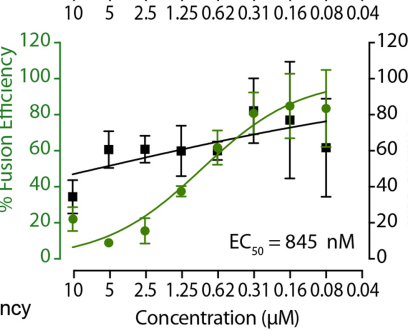

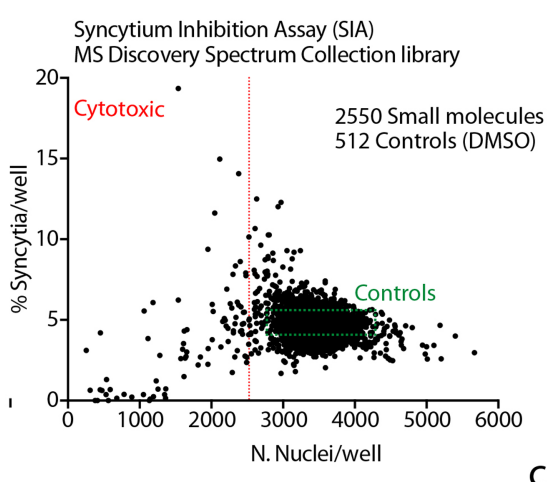

Syncytium Inhibition Assay (SIA) MS Discovery Spectrum Collection library

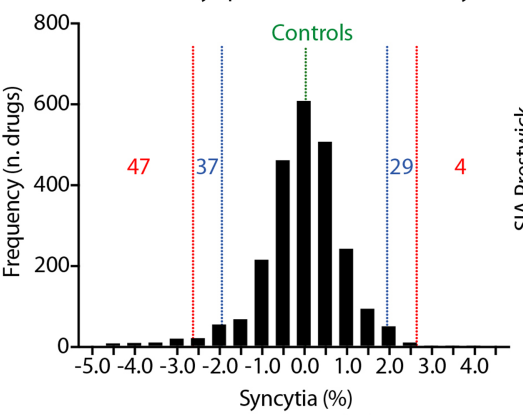

2351 non-cytotoxic drugs
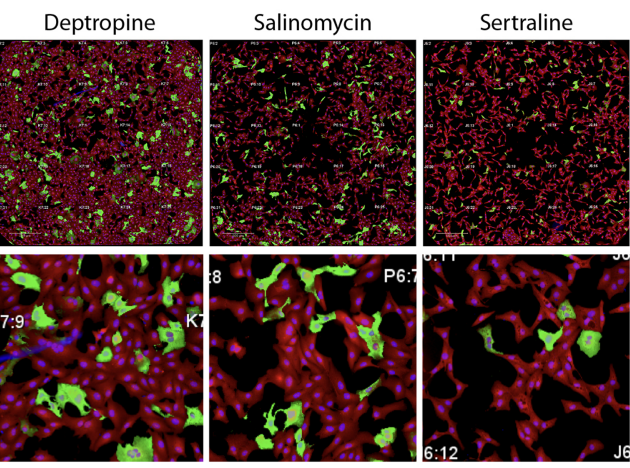

$2.39 \%$
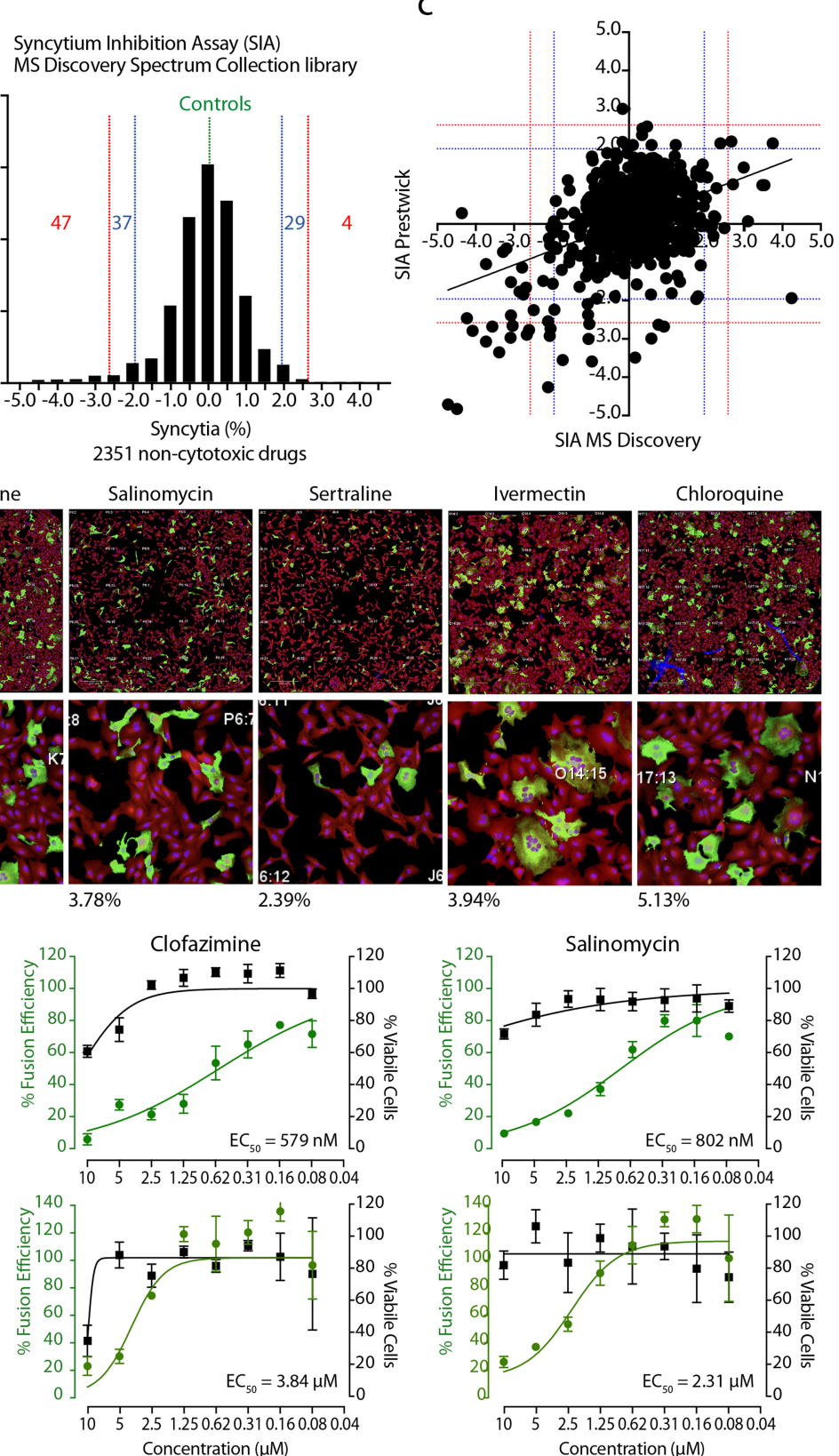

SIA MS Discovery

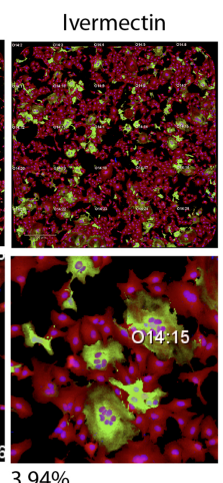

Chloroquine

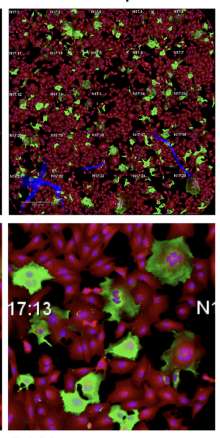

$5.13 \%$
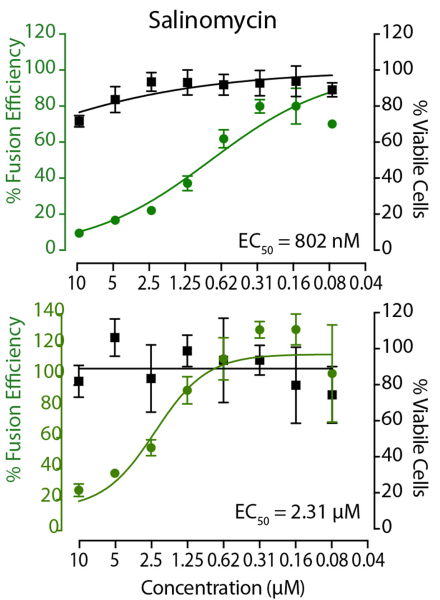

Extended Data Fig. 3 | See next page for caption. 
Extended Data Fig. 3 | Results of SIA screening. a, Analysis of CFIA results. Correlation chart between the percentage of syncytia per well and the total number of cells per well. Data are presented as in Extended Data Fig. 2e.

b, Distribution frequency of the screening results. Data are shown as in Extended Data Fig. 2f.c, Correlation chart for the common drugs between the two libraries. Data are shown as in Extended Data Fig. 2g. d, Representative immunofluorescence images for spike protein (green), cell body (red, using HCS CellMask DeepRed) and nuclei (blue, Hoechst) of cells treated with the indicated drugs increasing syncytia formation compared to control, DMSOtreated cells. The number of syncytia is shown at the bottom of each image pair as percentages of total nuclei. Scale bar, $500 \mu \mathrm{m}$. Representative images in one of six wells.e, Dose-response effect on syncytia formation of niclosamide, clofazimine and salinomycin. The graphs show the effect of different doses of the three drugs on syncytia formed by Vero and HEK/ACE2 cells in response to spike expression. Cells were transfected with pEC117-Spike-V5 and, $12 \mathrm{~h}$ later, treated with the indicated drug concentrations for additional $24 \mathrm{~h}$. Syncytia were quantified by high-content microscopy and are expressed as percentage of cell nuclei ( $n=6$ wells per dose; data are mean \pm s.d.). Cell viability was assessed by high-content counts of the number of nuclei in each well. 


\section{Article}

a

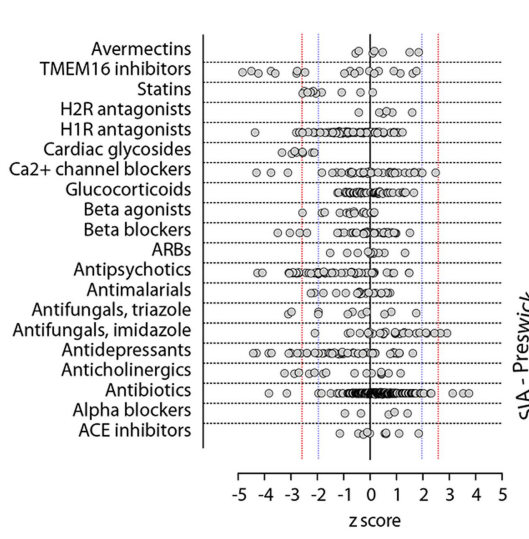

b

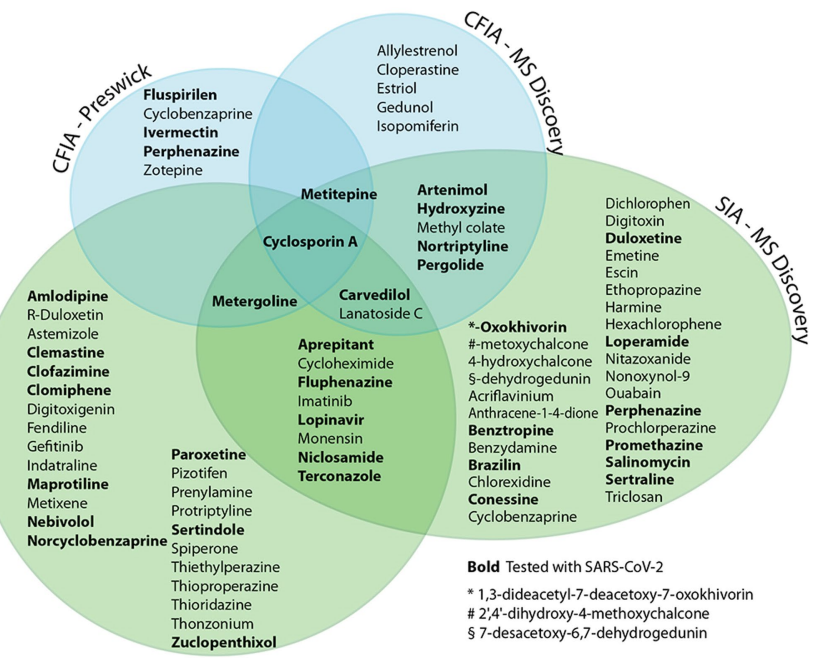

Extended Data Fig. 4 | Analysis of screening results. a, Effect of individual drugs in the SIA screening grouped according to therapeutic classes. Data are $z$-scores from the screening of both libraries (drugs present in both libraries are duplicated). The dotted lines are at $z$-scores \pm 2.58 (red) and \pm 1.96 (blue). Antipsychotics, antidepressants and $\mathrm{H}_{1}$ histamine receptor antagonists exerted negative effects on syncytia formation. Another inhibitory drug class included cardiac glycosides, as digitoxin, ouabain, lanatoside $\mathrm{C}$ and digitoxigenin were all in the $0.025 \%$ tail of the distribution when used at $10 \mu \mathrm{M}$.
On the contrary, antifungal drugs of the imidazole class had a trend to increase the frequency of syncytia. b, Venn diagram showing the drugs with $z$-scores $<-2.58$ from the results of the CFIA and SIA screenings using the two drug libraries, as indicated. Drugs in bold are those further tested on SARS-CoV-2 infection. CFIA and SIA are intrinsically different, as the former tests for plasma membrane fusion events between single, heterologous cells while the latter scores for the formation of larger syncytia. 
a

CAS N.

116539-60-7

88150-42-9

170729-80-3

81496-81-3

132-17-2, 86-13-5

6078-17-7

474-07-7

72956-09-3

50-63-5

14976-57-9

2030-63-9

5913-82-6, 546-06-5

59865-13-3

2169-75-7

100643-71-8

1672-46-4

20830-75-5

$146-56-5$

$1841-19-6$

2192-30-3

70288-86-7

34552-83-5, 53179-11-6

192725-17-0

10347-81-6

17692-51-2

20229-30-5

73573-88-3

99200-09-6

$50-65-7$

303-50-4

894-71-3, 72-69-5

110429-35-1

66104-22-1

58-39-9

55721-31-8; 53003-10-4 (acid)

106516-24-9

79559-97-0; 79617-96-2(base)

79902-63-9

67915-31-5

C

Control (DMSO)
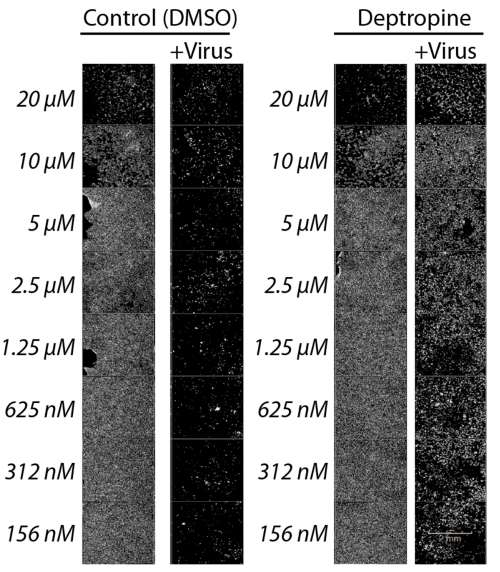

Sertraline
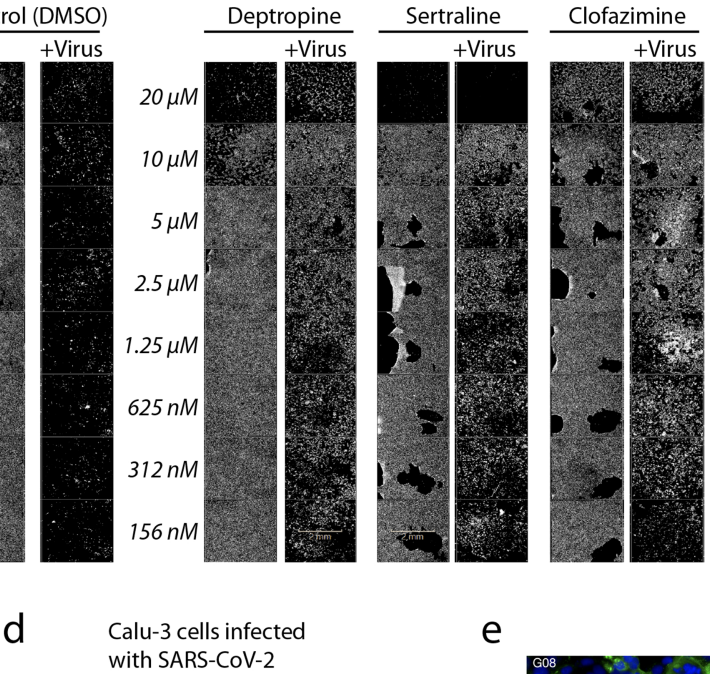

e
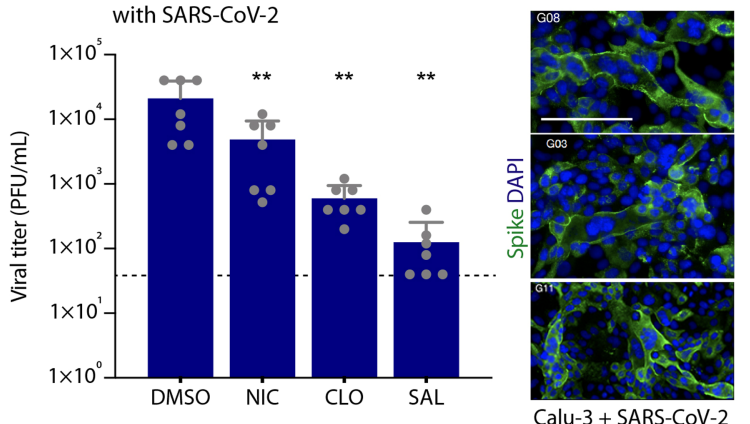

b

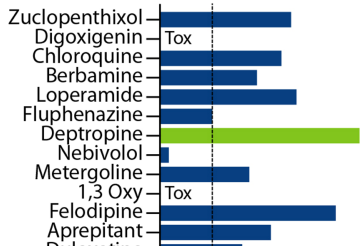

Clomiphene-

Cyclosporin A-

Brazilin-

Sertraline-

Nortryptiline-

Clofazimine-

Fluphenazine-

Artenimol-

Perphenazine--

Carvedilol-

Amlodipine

Amlodipine-
Ivermectin-

Metepine-

Benztropine-

Digoxin-Tox

Simvastatin-

Sertindole-

Clemastine--

Pergolide-Tox

Terconazole-

Norcyclobenzaprine-

Niclosamide- $-T$

Salinomycin-

Fluspirilen-

Maprotiline-

Connessine-

Mevastatin

Control-

Control-

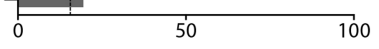

\% Survived cells@10 $\mu \mathrm{M}$

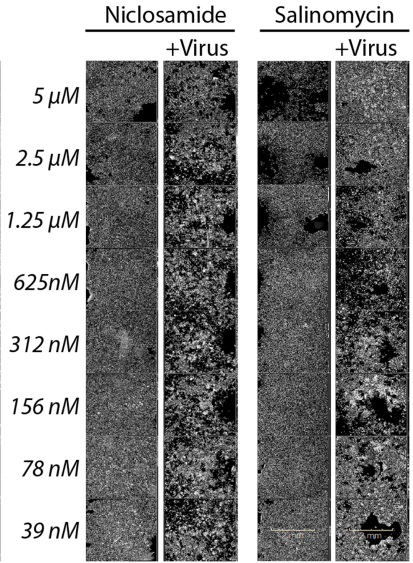

$f$

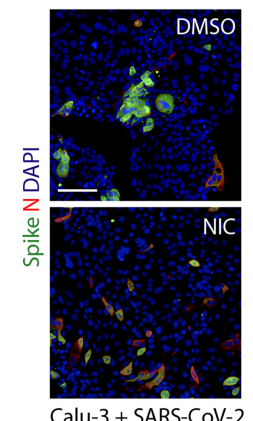

Extended Data Fig. 5 | See next page for caption. 


\section{Article}

Extended Data Fig. $5 \mid$ Cell protective ability of drugs against SARS-CoV-2. a, List of drugs (CAS number and chemical name) shortlisted from the syncytia assays and tested with infectious SARS-CoV-2.b, Effect of drugs on cell viability. Vero E6 cells were preincubated with a selection of drugs at $10 \mu \mathrm{M}$ for 2 h before $100 \mathrm{TCID}_{50}$ of IC19 was added. After 5 days, cells were fixed in $4 \%$ PFA. Cells survival was quantified by densitometry as the total cell area per well (average of two replicates). Drugs labelled with 'Tox' showed a cytotoxic effect at the used concentration independent of viral infection. Drugs in green were further tested for dose-dependent response.c, Dose-dependent cell protection of selected drugs against SARS-CoV-2 infection. Cells were preincubated with drugs or a negative DMSO control at different concentrations for $2 \mathrm{~h}$ before $100 \mathrm{TCID}_{50}$ of IC19 was added. After 3 days, cells were fixed in $4 \%$ PFA and cell survival was quantified by high-content microscopy as the total cell area per well using digital phase contrast (DPC) imaging $(n=3)$. The image shows one of the replicates. Niclosamide and salinomycin protected against virus-induced cell lysis across a wide range of concentrations from $5 \mu \mathrm{M}$ down to $39 \mathrm{nM}$ for niclosamide and salinomycin, whereas clofazimine showed a dose dependent cytoprotective effect above $1 \mu \mathrm{M}$. For sertraline and deptropine, the cytoprotective effect was only above
$2.5 \mu \mathrm{M}$ and close to the drug-alone cytotoxic effects (which were assessed separately; not shown). d, Inhibition of SARS-CoV-2 viral replication by selected drugs in Calu-3 respiratory cells. Cells were preincubated with drugs (niclosamide $2.5 \mu \mathrm{M}$, clofazimine $5 \mu \mathrm{M}$ and salinomycin $2.5 \mu \mathrm{M}$ ) for $2 \mathrm{~h}$ and then infected with SARS-CoV-2. After $1 \mathrm{~h}$, cells were washed with PBS and then cultured in fresh drug-containing medium for a further $48 \mathrm{~h}$. Virus production in the culture supernatants was quantified by plaque assay using Vero E6 cells. The graphs show virus production in the culture supernatants quantified by plaque assay using Vero $E 6$ cells (mean \pm s.e.m.; $n=7$ ). ${ }^{* *} P<0.01$, one-way ANOVA with Bonferroni post hoc correction. e, Representative images of syncytial Calu- 3 cells positive for SARS-CoV-2 infection. Cells were immunostained for spike protein (green), and nuclei (blue).f, Inhibition of syncytia by niclosamide after SARS-CoV-2 infection. Calu- 3 cells were preincubated with niclosamide $2.5 \mu \mathrm{M}$ and then infected with SARS-CoV-2 in the presence of the drug. After $1 \mathrm{~h}$, cells were washed with PBS and then cultured in fresh drug-containing medium. After $48 \mathrm{~h}$, cells were immunostained for spike (green), nucleocapsid (red) and nuclei (blue). Scale bar, $200 \mu \mathrm{m}$. 

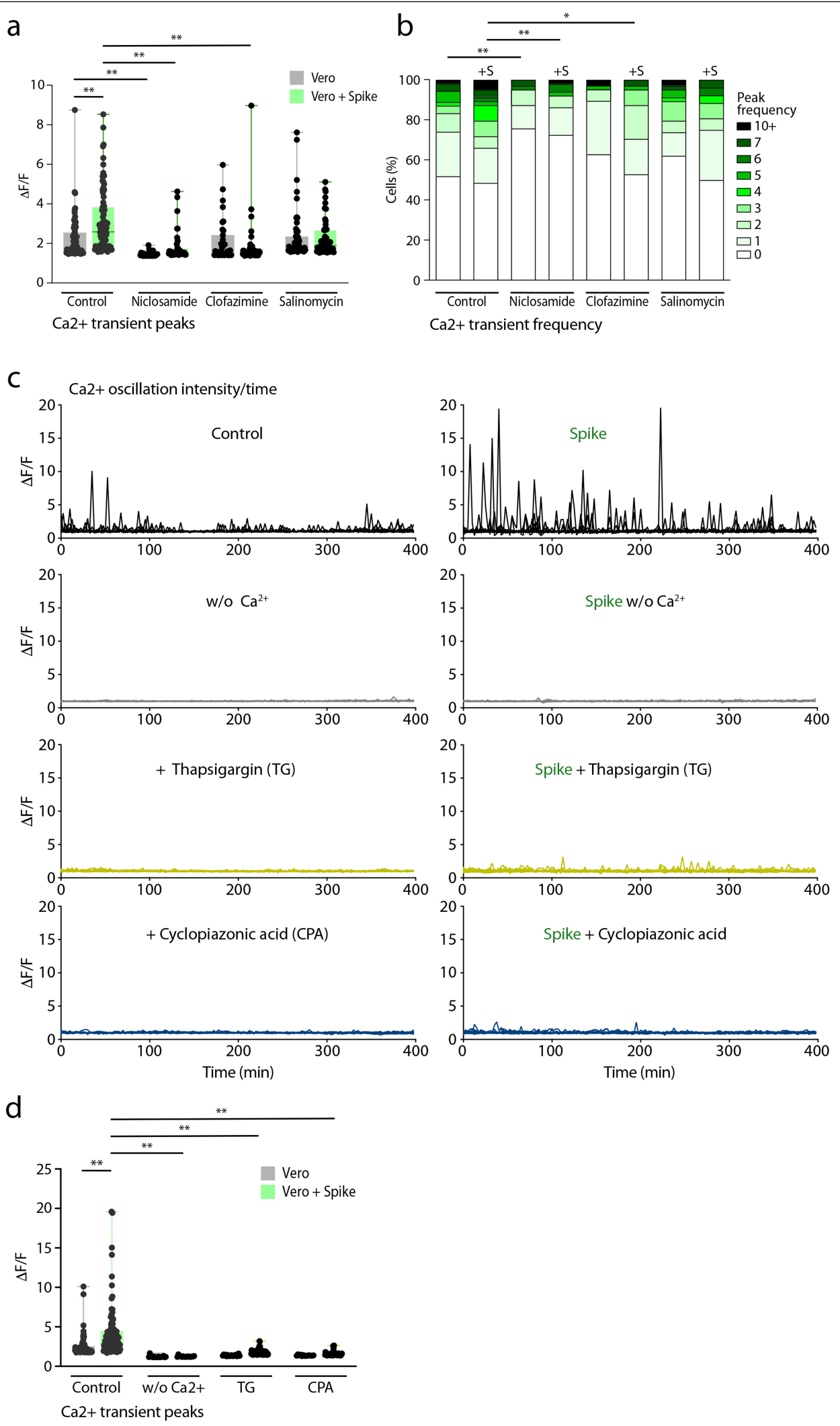

Extended Data Fig. 6 | See next page for caption. 


\section{Article}

Extended Data Fig. 6 | Effect of drugs on $\mathrm{Ca}^{2+}$ oscillations. a, Amplitude of calcium transient peaks per group of $4 \mathrm{GCaMP}^{+}$cells in average in at least twelve $180 \mu \mathrm{m}^{2} \mathrm{ROI}$ per condition. Vero cells co-transfected with GCaMP6s and either an empty vector (grey bars) or with spike protein (green bars) and treated with the specified drugs. Data are expressed as $\Delta F / F$; boxes denote the 25 th -75 th percentiles and median, whiskers denote the minimum-maximum values; ${ }^{* *} P<0.01$, Kruskal-Wallis, two-sided, with Dunn's correction for multiple comparisons. b, Distribution of transient frequencies of single cells in $400 \mathrm{~min}$ analysis. Data are expressed as percentage of cells. Results from at least 50 cells per condition are shown. ${ }^{*} P<0.05,{ }^{* *} P<0.01$, Kruskal-Wallis, two-sided, with
Dunn's correction for multiple comparisons. c, Calcium transients over time in Vero cells co-transfected with GCaMP6s and either an empty vector (left) or with spike (right) and the indicated treatment. Data are expressed as $\Delta F / F$ over time (min); every line is one of at least twelve $180 \mu \mathrm{m}^{2} \mathrm{ROI}$ per condition, representing a group of $4 \mathrm{GCaMP}^{+}$cells on average. $\mathbf{d}$, Amplitude of calcium transient peaks per group of $4 \mathrm{GCaMP}^{+}$cells on average in at least $12180 \mu^{2}$ ROI per condition. Vero cells co-transfected with GCaMP6s and either an empty vector (grey bars) or with spike (green bars) and treated as indicated. Data are expressed as $\Delta F / F$; boxes as in $\mathbf{a} .{ }^{* *} P<0.01$, Kruskal-Wallis, two-sided, with Dunn's correction for multiple comparisons. 

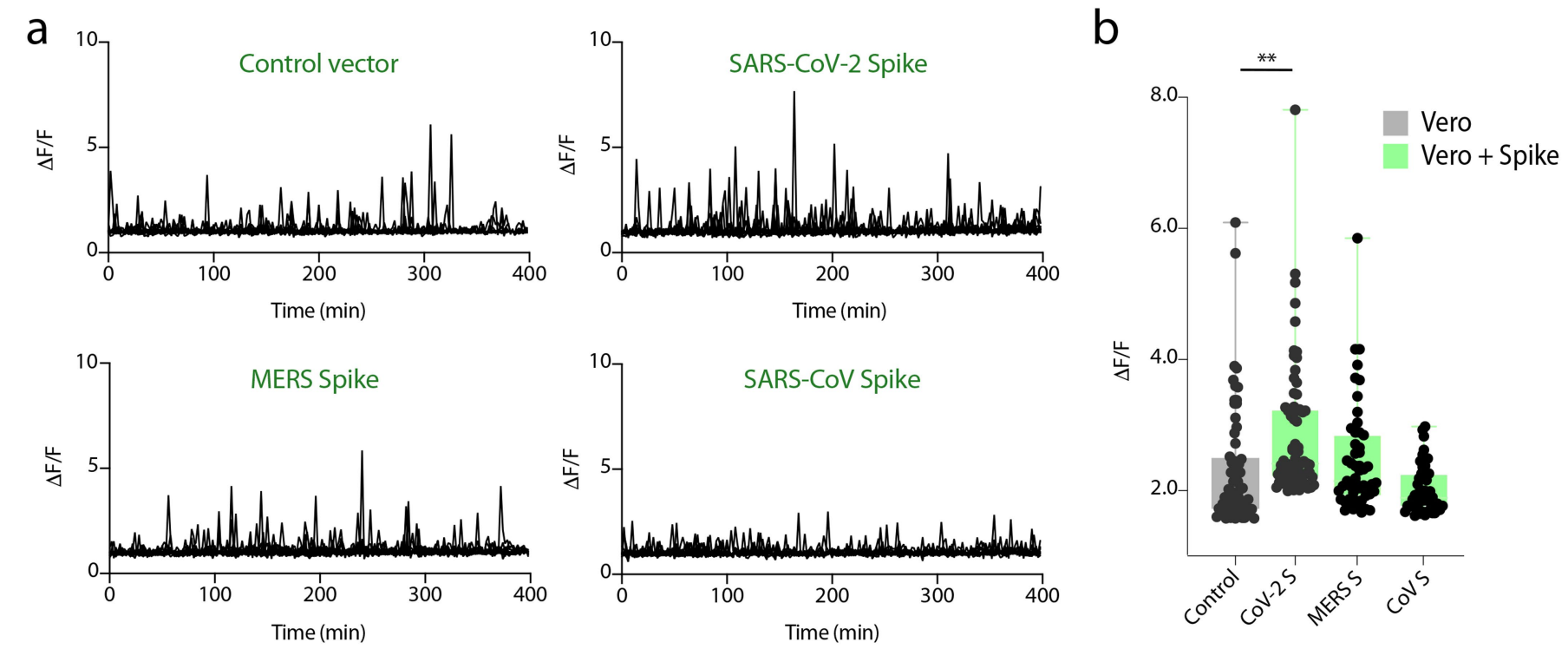

d

C
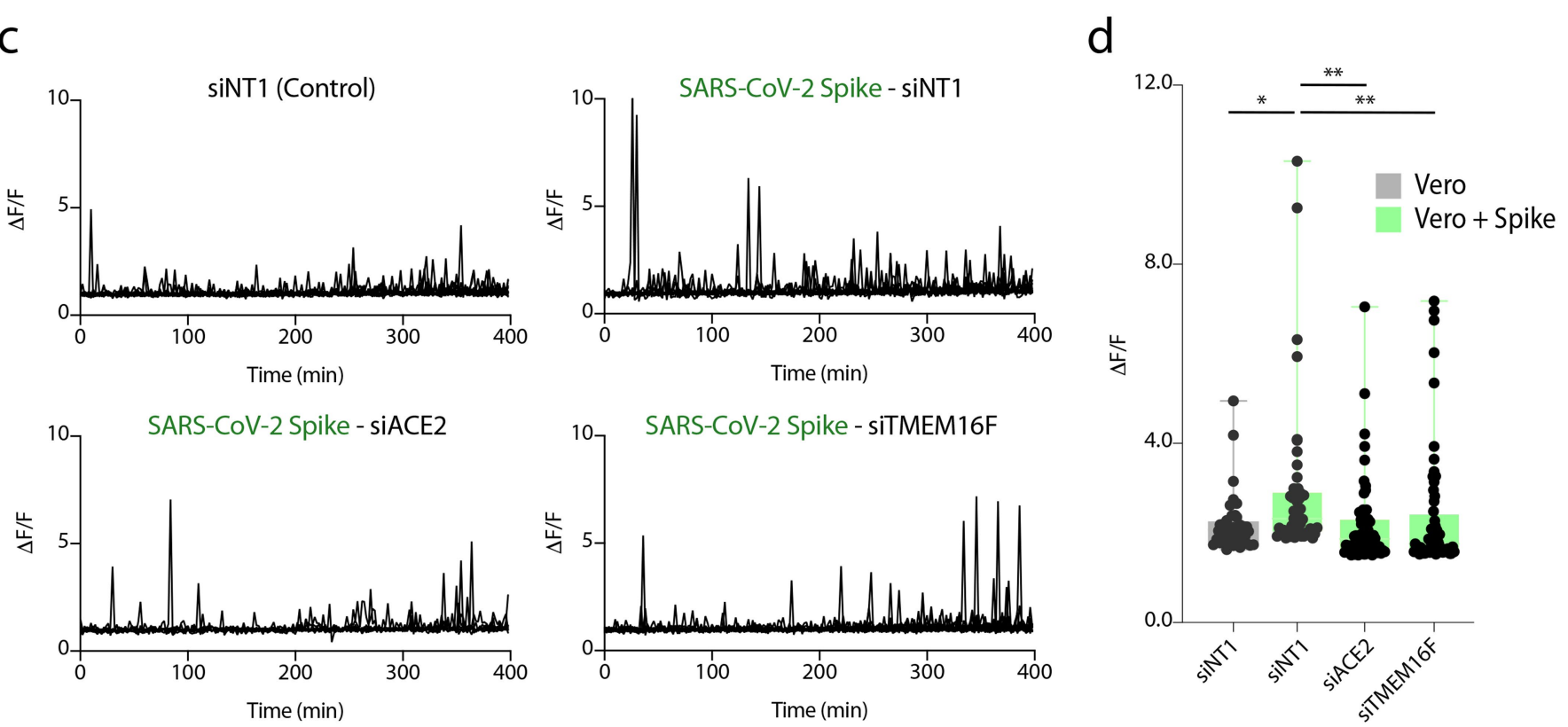

Extended Data Fig. $7 \mid$ Induction of $\mathrm{Ca}^{2+}$ oscillations by coronavirus Spike proteins and upon ACE2 and TMEM16F knockdown. a, c, Calcium transients over time in Vero cells co-transfected with GCaMP6s and the indicated plasmids and siRNAs. Data are expressed as $\Delta F / F$ over time ( $\mathrm{min}$ ); every line is 1

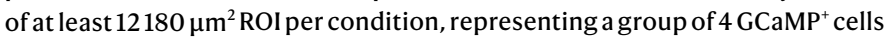

on average. b, d, Amplitude of calcium transient peaks per group of $4 \mathrm{GCaMP}^{+}$ cells in average in at least $12180 \mu \mathrm{m}^{2} \mathrm{ROI}$ per condition. Data are expressed as $\Delta F / F$; boxes as in Extended Data Fig. 6a. ${ }^{*} P<0.05,{ }^{* *} P<0.01$, Kruskal-Wallis, two-sided, with Dunn's correction for multiple comparisons. 
a
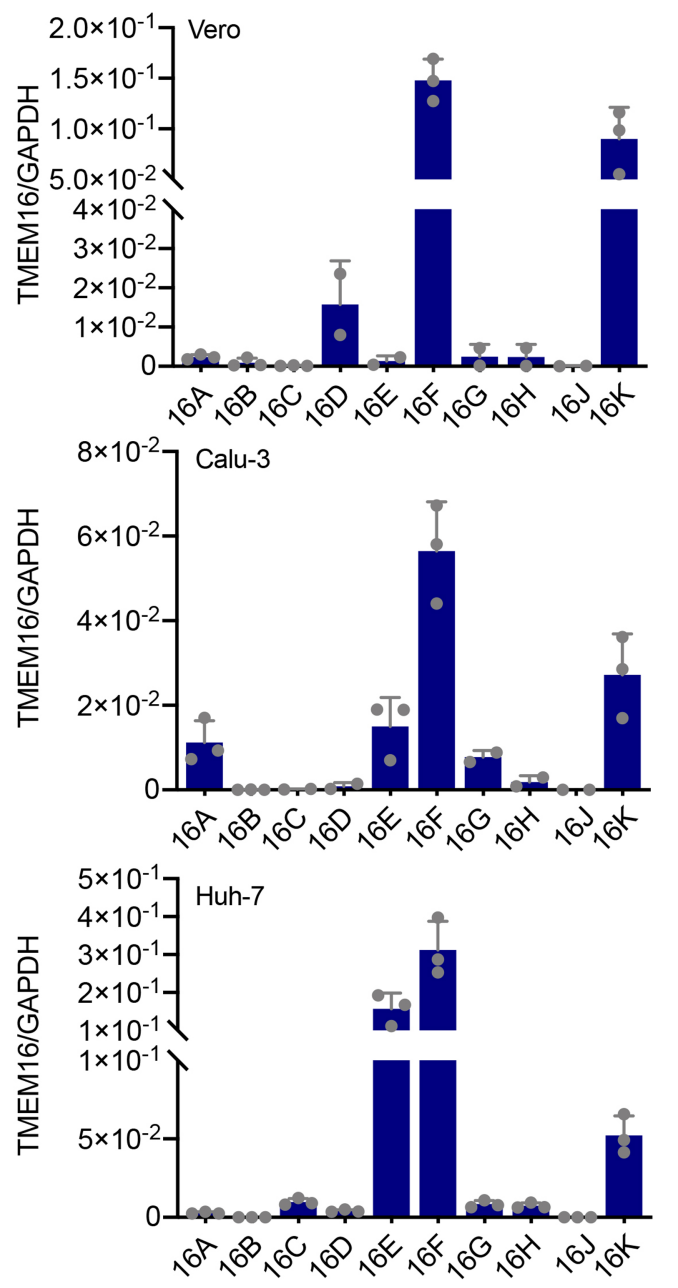

b

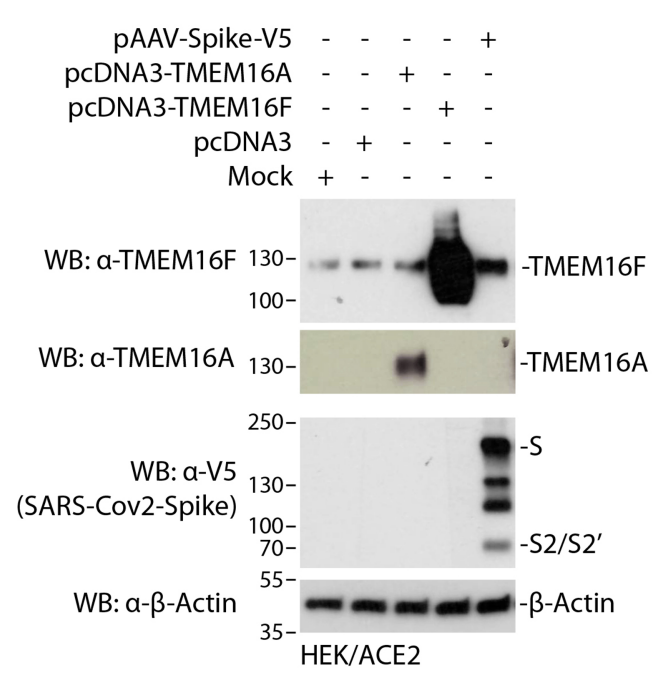

Extended Data Fig. 8 | Levels of expression of TMEM16 family members. a, Expression profiles of the 10 known TMEM16 proteins in different cell types and primary human respiratory cells. RNA was prepared from the indicated cell lines and from primary bronchial human airway epithelial cells. Levels of mRNA quantified by qPCR are expressed relative to GAPDH mRNA. Data are mean \pm s.e.m. of three independent experiments. b. Western blot showing the levels of TMEM16F and TMEM16A in basal conditions and upon overexpression, and after transfection of V5-tagged SARS-CoV-2 Spike. $\beta$-actin was used as a
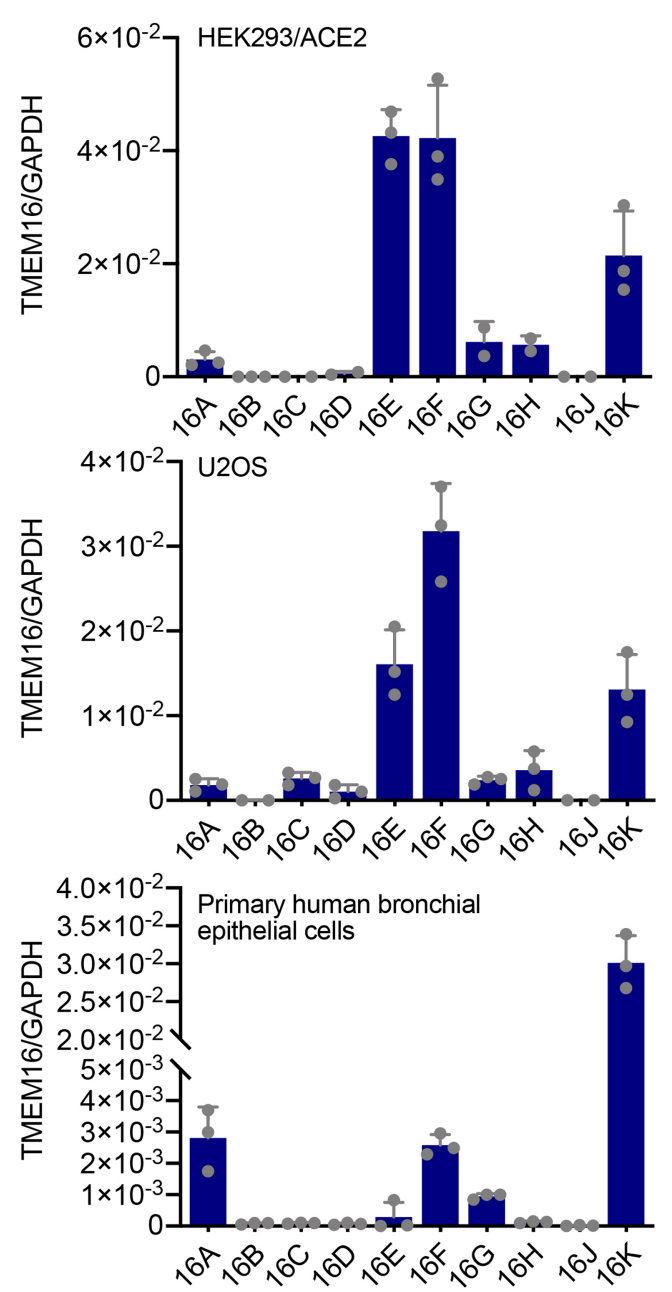

C
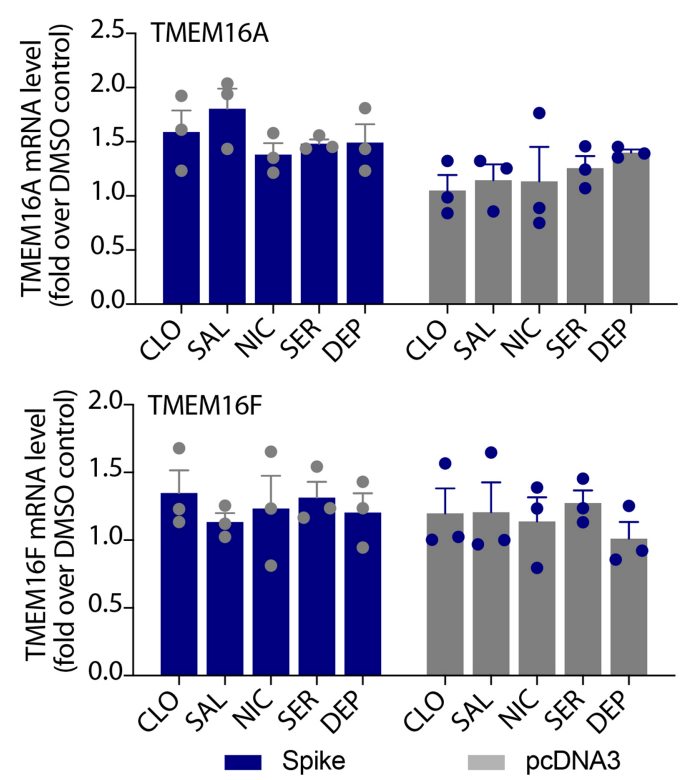

loading control. Representative blot of three independent repetitions. c, Expression of TMEM16A (top) and TMEM16F (bottom) in the presence of the top 5 selected drugs. RNA was prepared from the HEK293/ACE2 cells transfected either with spike protein or control plasmids in the presence of the indicated drugs for $24 \mathrm{~h}$. The mRNA levels of TMEM16A and TMEM16F were quantified by qPCR and are expressed as fold over control condition (DMSO), after normalization over the GAPDH housekeeping mRNA. Data are mean \pm s.e.m. of three independent experiments. 


\section{a}

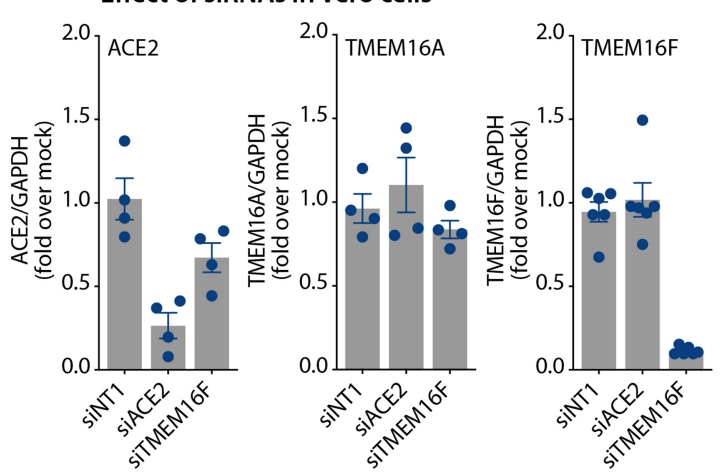

Effect of siRNAs in HEK293 cells
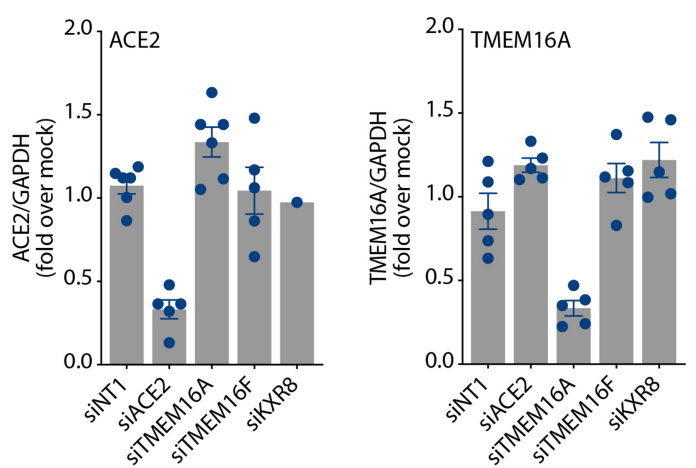

b

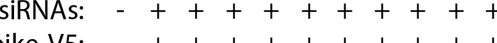

pAAV-Spike-V5: -++++++++++ pCDNA3:

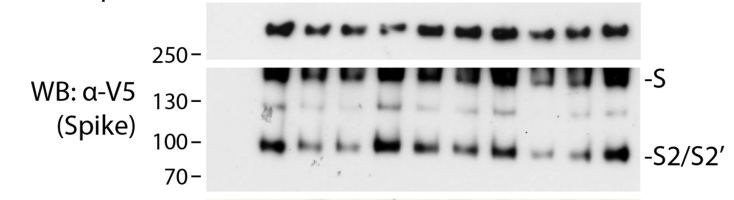

WB: ${ }^{130-}$

a-ACE2 $100-$
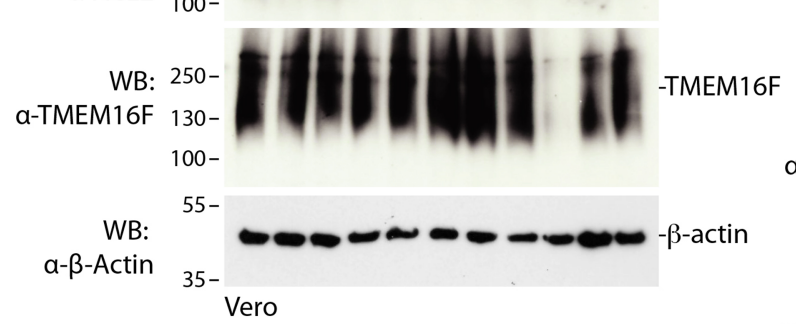

Effect of siRNAs in Calu- 3 cells
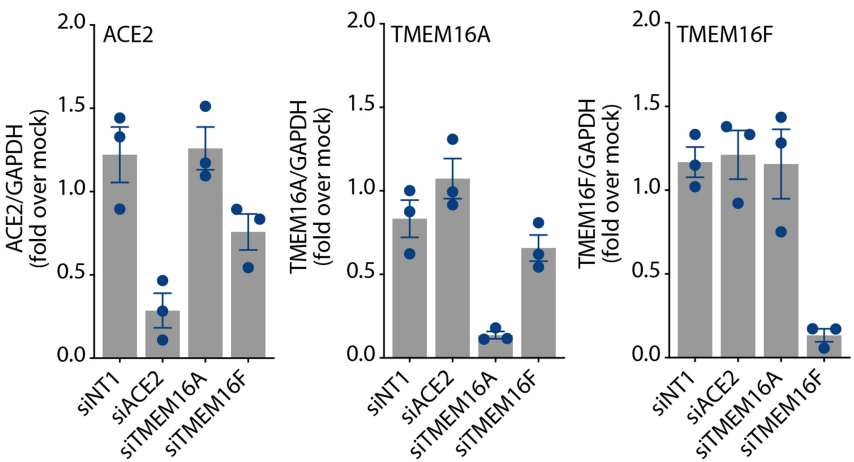

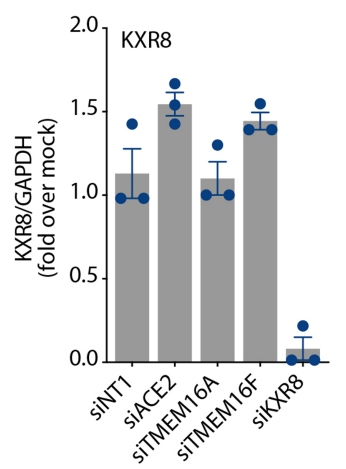

ก $\overleftarrow{0}$ :

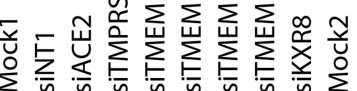

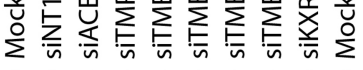

siRNAs: -++++++++++

pAAV-Spike-V5: -++++++++++

pcDNA3: +

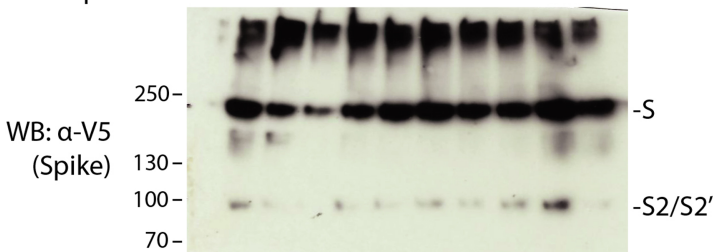

WB: ${ }^{130-}$ - $100-0000$-ACE2

WB: $\begin{aligned} & 250- \\ & 130-\end{aligned}$ a-TMEM16F

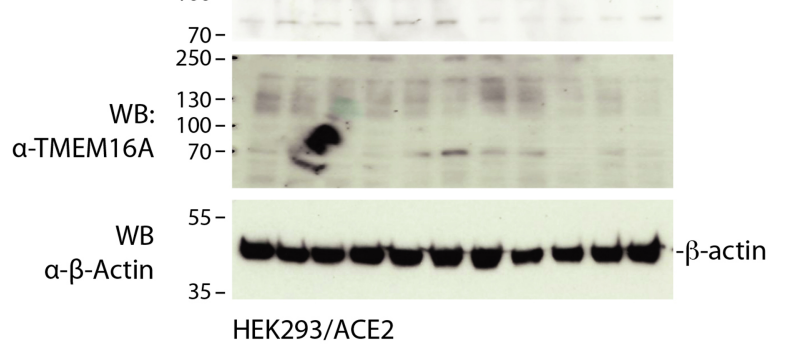

Extended Data Fig. 9 |See next page for caption. 


\section{Article}

Extended Data Fig. 9 | Expression of TMEM16A, TMEM16F and ACE2 in

different experimental conditions. a, Levels of expression of the genes investigated in this study upon their individual knockdown in Vero, HEK293/ ACE 2 and Calu-3 cells. RNA was prepared from the different cell lines after transfection with the indicated siRNAs (siNT1-control non-targeting siRNA1) and $m R N A$ levels were quantified by qPCR. Data are expressed as fold change compared with mock-treated cells after normalized over the $G A P D H$ housekeeping mRNA. Data are mean \pm s.e.m. of three independent experiments. b, Western blotting analysis showing the levels of ACE2 and
TMEM16F in the presence of spike protein after silencing selected genes ( $A C E 2$, TMPRSS2, TMEM16A, TMEM16B, TMEM16E, TMEM16F and XKR8). The amount of spike, ACE2 and TMEM16F measured by immunoblotting is shown after cell treatment with the respective siRNAs. The levels of spike, ACE2 and TMEM16F proteins were assessed by immunoblotting with anti-V5, anti-ACE2 and antiTMEM16F antibodies respectively. $\beta$-actin was used as a loading control. Representative blot of three independent repetitions. c, As in b in HEK293/ ACE2 cells. The blot with the anti-TMEM16A antibody did not detect any band of the expected mass (Extended Data Fig. 7b). 

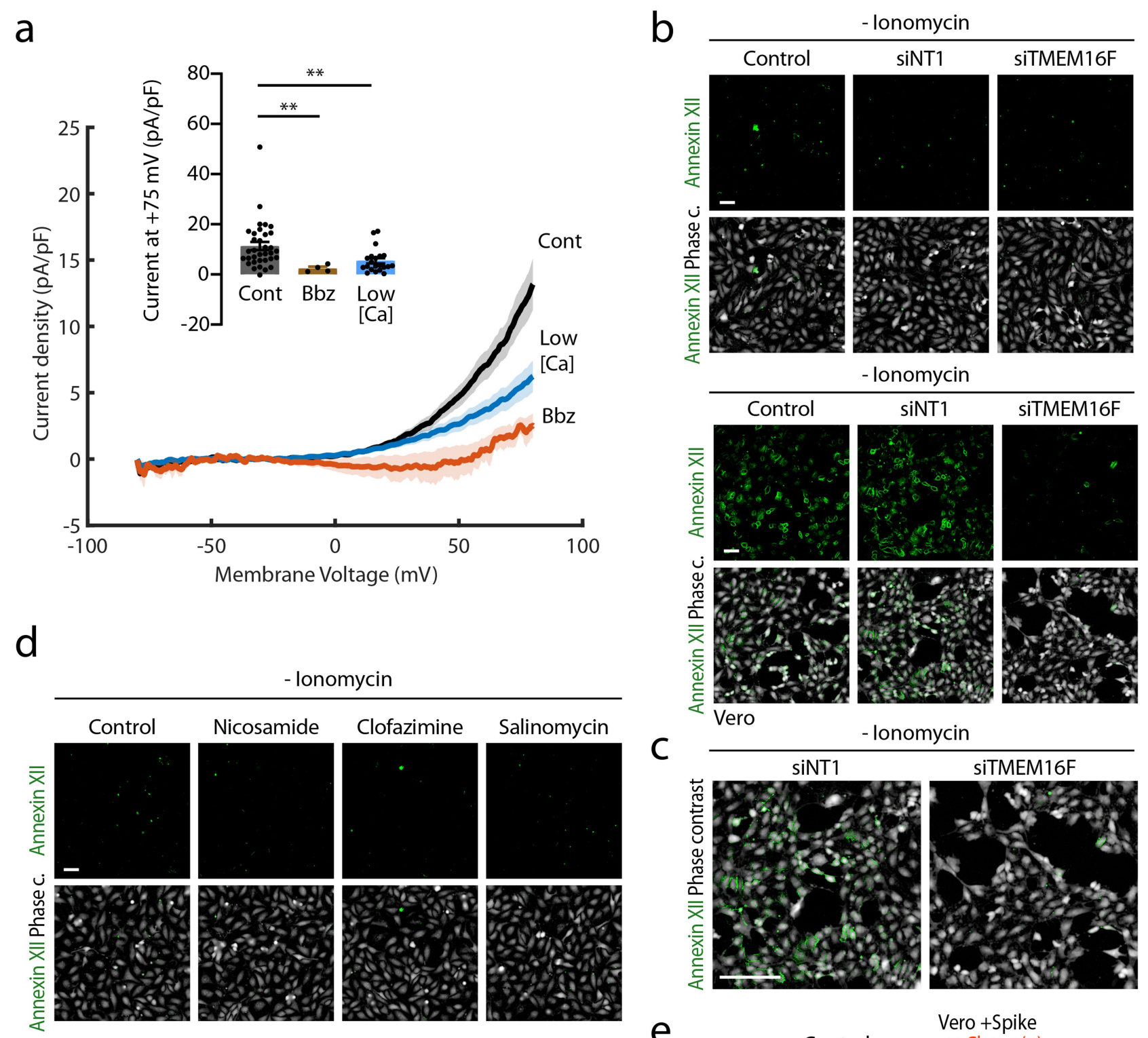

e

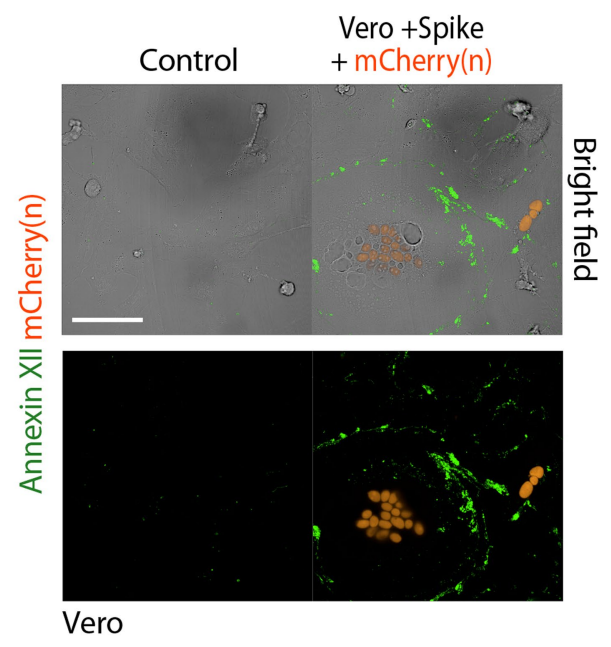

Extended Data Fig. 10 |See next page for caption. 


\section{Article}

Extended Data Fig. $10 \mid$ Current density and phosphatidylserine

externalization. a, Results of whole-cell voltage-clamp recordings of HEK293

cells measuring current density in response to a voltage ramp. Currents were measured using a 500-ms voltage ramp from -80 to $+80 \mathrm{mV}$ in control cells (Cont; black trace, $n=34$; controls as in Fig. $3 \mathrm{c}-\mathrm{e}$; recorded with $28 \mathrm{mM}$ intracellular calcium), in cells treated with the benchmark TMEM16 channel antagonist benzbromarone $(\mathrm{Bbz}, 10 \mathrm{mM}$; brown trace, $n=3)$ or recorded with a low intracellular calcium concentration (low [Ca], $0.5 \mathrm{mM}$; blue trace, $n=21$ ) $(n=4)$. The inset shows the current density measured at $+75 \mathrm{mV} .{ }^{* *} P<0.01$, Kruskal-Wallis, two-sided, with Dunn's post hoc multiple comparisons. All values are displayed as mean \pm s.e.m. b, c, Inhibition of phosphatidylserine exposure after treatment with TMEM16F siRNA and indicated drugs.

Representative image of Vero cells reverse-transfected with the indicated
siRNAs and stained for annexin XII without (top) or with (bottom) ionomycin induction $(10 \mu \mathrm{M})$. Annexin in green, phase-contrast in grey. Scale bar, $500 \mu \mathrm{m}$. Enlargement in c. Selected images and quantification are in Fig. 3f, g.

d, Representative image of Vero cells treated with $100 \mathrm{nM}$ niclosamide, $500 \mathrm{nM}$ clofazimine or $500 \mathrm{nM}$ salinomycin and stained for annexin XII without (top) or with (bottom) ionomycin induction $(5 \mu \mathrm{M})$. Annexin in green, phase-contrast in grey. Scale bar, $500 \mu \mathrm{m}$. Enlargement in b. Selected images and quantification in Fig. 3h, i.e, Annexin XII reactivity (phosphatidylserine externalization) of syncytia expressing the spike protein. Cells were transfected with the spikeexpressing plasmid and a plasmid expressing mCherry carrying a nuclear localization signal (orange nuclei). Scale bar, $500 \mu \mathrm{m}$. Representative image of over 10 syncytia in at least 3 independent experiments. 

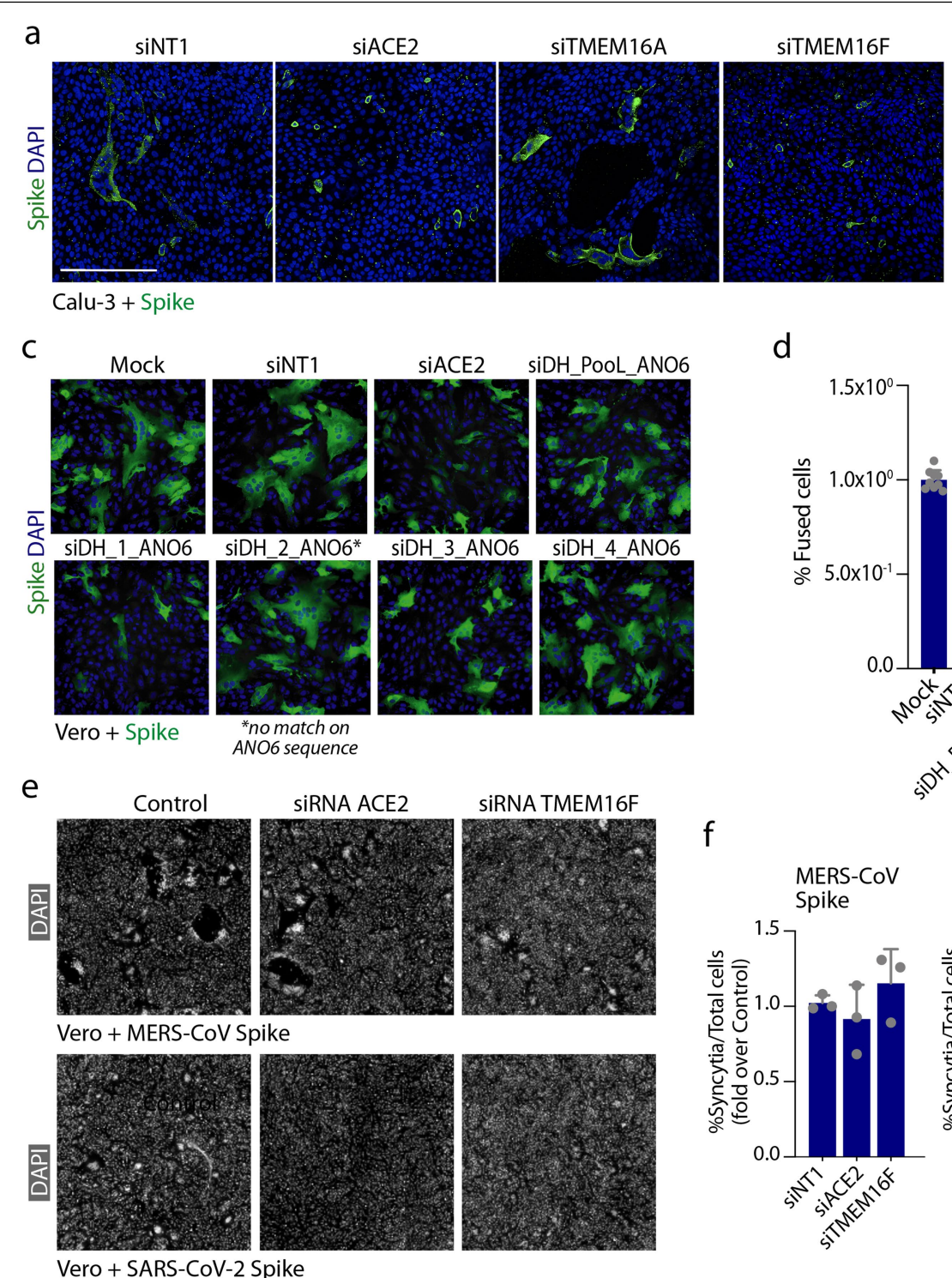

g

Control

TMEM16F
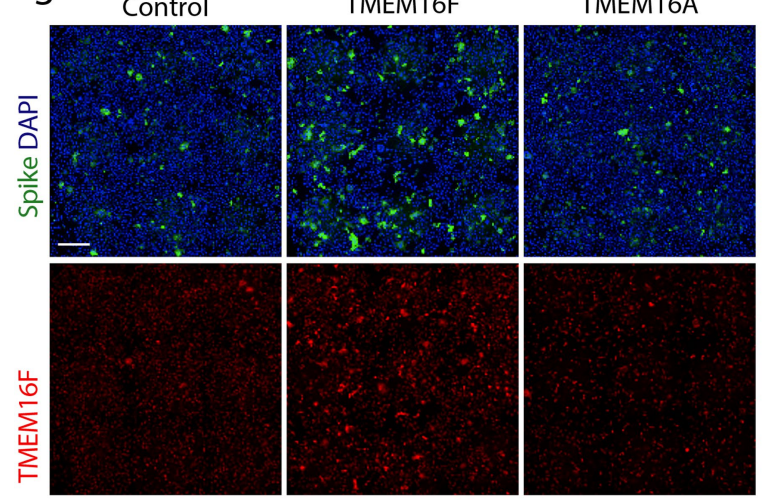

HEK293/ACE2 + Spike + TMEM16 Low magnification d
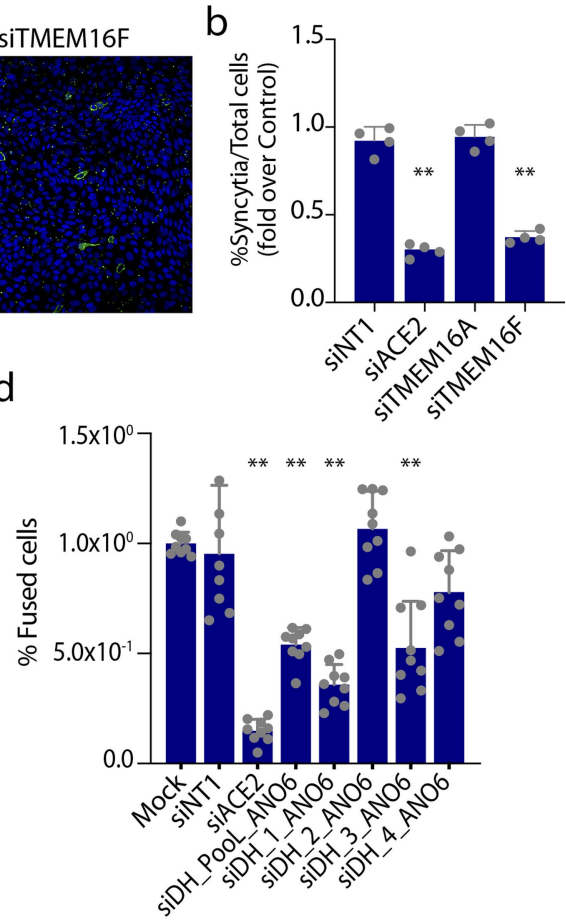

f
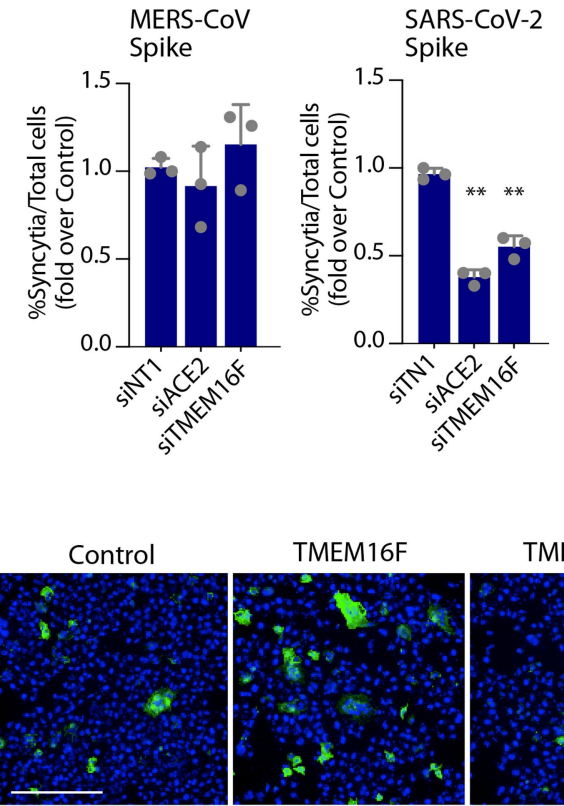

TMEM16F

TMEM16A
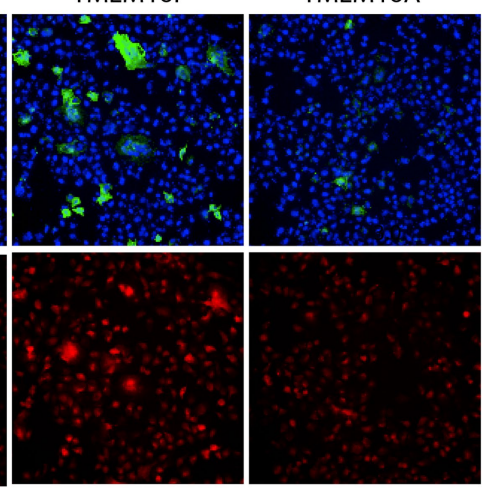

HEK293/ACE2 + Spike + TMEM16 High magnification

Extended Data Fig. 11|See next page for caption. 


\section{Article}

Extended Data Fig. 11 | TMEM16F is involved in SARS-CoV-2 spike-induced syncytia formation. $\mathbf{a}, \mathbf{b}$, Inhibition of syncytia formation in Calu- 3 cells by the downregulation of TMEM16F. Calu-3 cells were first silenced for each of the indicated genes or treated with siNT1 (non-targeting siRNA1 as negative control) and then, after $24 \mathrm{~h}$, transfected to express the spike protein. After an additional $24 \mathrm{~h}$, cells were immunostained for spike (green) and nuclei (blue). Representative images are in a, quantification in b. Data (mean \pm s.d.; $n=3)$ are plotted as percentage of syncytia (cell area $\geq 20,000 \mu \mathrm{m}^{2}$ ) normalized to the total number of cells and expressed as fold change compared to mock (lipidonly)-treated cells. Scale bar, $500 \mu \mathrm{m} .{ }^{*} P<0.05,{ }^{* *} P<0.01$, one-way ANOVA with Dunnett post hoc correction. c, d, Effect of individual siRNAs forming the Dharmacon siRNA Pool against TMEM16F. The picture shows the efficiency of syncytia formation after transfection of spike cDNA in Vero cells in which TMEM16F was downregulated using the 4-siRNA pool (which was used in all the other experiments in this Article) or the individual siRNAs forming this pool (siDH_1-4). We found that the commercial siDH_2 siRNA does not match the TMEM16F sequence. Data in $\mathbf{d}$ are mean \pm s.d., plotted as percentage of syncytia (cell area $\geq 20,000 \mu \mathrm{m}^{2}$ ) normalized on the total number of cells and expressed as fold compared to mock (lipid-only)-treated cells. ${ }^{* *} P<0.01$, one-way ANOVA with Dunnett post hoc correction. e, f, Effect of selected siRNAs on MERS-CoVand SARS-CoV-2-induced syncytia formation. Vero cells were first silenced for each of the indicated genes (ACE2 and TMEM16F) or treated with siNT1 (nontargeting siRNA1 as negative control) and then, after $24 \mathrm{~h}$, transfected to express the either MERS or SARS-CoV spike protein. After an additional $24 \mathrm{~h}$, cells were immunostained for nuclei (white). Representative images are in in the panels on the left, quantification in the bar chart on the right. Data (mean \pm s.e.m.; $n=3$ ) are plotted as percentage of syncytia normalized on the total number of cells and expressed as fold change compared with mock (lipidonly)-treated cells. ${ }^{*} P<0.05,{ }^{* *} P<0.01$, one-way ANOVA with Bonferroni post hoc correction. g, TMEM16F overexpression induces spike-mediated syncytia formation. HEK293 or ACE2 cells were co-transfected with human TMEM16A or TMEM16F together with a spike-expressing plasmid. After an additional $24 \mathrm{~h}$, cells were immunostained for spike protein (green), TMEM16F (red) and nuclei (blue). Selected images and quantification in Fig. 31, m. Scale bar, $200 \mu \mathrm{m}$. 


\section{Reporting Summary}

Nature Research wishes to improve the reproducibility of the work that we publish. This form provides structure for consistency and transparency in reporting. For further information on Nature Research policies, see our Editorial Policies and the Editorial Policy Checklist.

\section{Statistics}

For all statistical analyses, confirm that the following items are present in the figure legend, table legend, main text, or Methods section.

n/a Confirmed

$\square$ The exact sample size $(n)$ for each experimental group/condition, given as a discrete number and unit of measurement

$\square$ A statement on whether measurements were taken from distinct samples or whether the same sample was measured repeatedly

The statistical test(s) used AND whether they are one- or two-sided

$\square$ Only common tests should be described solely by name; describe more complex techniques in the Methods section.

Х $\square$ A description of all covariates tested

$\square$ \A description of any assumptions or corrections, such as tests of normality and adjustment for multiple comparisons

$\square$ A full description of the statistical parameters including central tendency (e.g. means) or other basic estimates (e.g. regression coefficient)

AND variation (e.g. standard deviation) or associated estimates of uncertainty (e.g. confidence intervals)

For null hypothesis testing, the test statistic (e.g. $F, t, r$ ) with confidence intervals, effect sizes, degrees of freedom and $P$ value noted

Give $P$ values as exact values whenever suitable.

Х $\square$ For Bayesian analysis, information on the choice of priors and Markov chain Monte Carlo settings

Х $\square$ For hierarchical and complex designs, identification of the appropriate level for tests and full reporting of outcomes

Х $\square$ Estimates of effect sizes (e.g. Cohen's $d$, Pearson's $r$ ), indicating how they were calculated

Our web collection on statistics for biologists contains articles on many of the points above.

\section{Software and code}

Policy information about availability of computer code

Data collection Image analysis for high content microscopy analysis was performed using the Harmony v 4.9 software package (PerkinElmer)

Data analysis Statistical analysis was performed using GraphPad Prism 8.0 or 9.0. Analysis of electrophysiology results carried out using Matlab v. R2019a For manuscripts utilizing custom algorithms or software that are central to the research but not yet described in published literature, software must be made available to editors and reviewers. We strongly encourage code deposition in a community repository (e.g. GitHub). See the Nature Research guidelines for submitting code \& software for further information.

\section{Data}

Policy information about availability of data

All manuscripts must include a data availability statement. This statement should provide the following information, where applicable:

- Accession codes, unique identifiers, or web links for publicly available datasets

- A list of figures that have associated raw data

- A description of any restrictions on data availability

There are no restrictions on data availability. CAS numbers for the investigated drugs are reported in the manuscript. All data are reported in the manuscript main text or supplementary material 


\section{Field-specific reporting}

Please select the one below that is the best fit for your research. If you are not sure, read the appropriate sections before making your selection.

$\bigotimes$ Life sciences $\quad \square$ Behavioural \& social sciences $\quad \square$ Ecological, evolutionary \& environmental sciences

For a reference copy of the document with all sections, see nature.com/documents/nr-reporting-summary-flat.pdf

\section{Life sciences study design}

All studies must disclose on these points even when the disclosure is negative.

Sample size No sample-size pre-determination was performed. The HTS screenings were performed in two biological replicates with 3 wells/drug in 384 well plates. All the other experiments involving the use of drugs, siRNAs or expression plasmids were performed in 96-well plates in which each condition was tested in 3-8 independent wells. These sample sizes are in agreement with published reports on the effects of the individual treatments on the respective targets (cf. specific citations in the manuscript).

Data exclusions Drugs showing toxicity on cell viability in the two HTS screenings were excluded from further analysis. Toxicity was defined as a reduction in the number of nuclei $\geq 2$ standard deviations less than the average of all drugs.

Replication All attempts at replication were successful by our best efforts. All experiments were performed at least in triplicate (and often more times) independently with reproducible results

Randomization Experiments were performed on cultured cells uniformly plated in 96-well plates or glass slides (for electrophysiology), with random allocation of treatment (virus, chemicals, siRNAs and plasmids).

Blinding Blinding was not applicable to our investigation, given the nature of the reagents used (chemicals, siRNAs and plasmids). All the critical experiments were repeated independently by at least two of the investigators.

\section{Reporting for specific materials, systems and methods}

We require information from authors about some types of materials, experimental systems and methods used in many studies. Here, indicate whether each material, system or method listed is relevant to your study. If you are not sure if a list item applies to your research, read the appropriate section before selecting a response.

Materials \& experimental systems

Methods

$\mathrm{n} / \mathrm{a}$ Involved in the study

$\square$ \ Antibodies

$\square \bigotimes$ Eukaryotic cell lines

Х $\square$ Palaeontology and archaeology $\mathrm{n} / \mathrm{a}$ Involved in the study

$\bigotimes \square$ ChIP-seq

Х $\square$ Animals and other organisms

Х $\square$ Flow cytometry

$\square$ Human research participants

$\square$ \Clinical data

$\bigotimes \square$ Dual use research of concern

\section{Antibodies}

Antibodies used

Antibodies against the following proteins were used: TMEM16A (Abcam, ab64085), TMEM16F (Abcam ab234422 and Sigma-Aldrich HPA038958-100UL), ACE2 (Abcam ab87436 and ab15348), V5 (Thermo Fisher Scientific R96025), V5-488 (Thermo Fisher Scientific 377500A488), mouse-HRP (Abcam ab6789), rabbit-HRP (Abcam ab205718), b-actin-HRP (Sigma-Aldrich A5316), Napsin (Roche 760-4867), Surfactant B (Thermo Fisher Scientific MS-704-P0), mouse-Biotin (Vector Laboratories BA-9200), SARS-CoV-2 Spike protein (GeneTex GTX632604), SARS-CoV-2 Nucleocapsid antibody (Sino Biological 40143-R001)

Validation

Antibodies against TMEM16A (Abcam, ab64085), TMEM16F (Abcam ab234422 and Sigma-Aldrich HPA038958-100UL), ACE2 (Abcam ab87436 and ab15348), V5 (Thermo Fisher Scientific R96025), V5-488 (Thermo Fisher Scientific 377500A488), b-actin-HRP (SigmaAldrich A5316), Napsin (Roche 760-4867), Surfactant B (Thermo Fisher Scientific MS-704-P0), mouse-Biotin (Vector Laboratories BA-9200), SARS-CoV-2 Spike protein (GeneTex GTX632604) and SARS-CoV-2 Nucleocapsid antibody (Sino Biological 40143-R001) were validate were validated according to individual datasheets provided by the manufacturers.

\section{Eukaryotic cell lines}

Policy information about cell lines

Cell line source(s)

Vero(WHO) Clone 118 cells (ECACC 88020401), Vero E6 (provided by Andrew Davidson and David Matthews, University of 
Cell line source(s)

Authentication

Mycoplasma contamination

Commonly misidentified lines

(See ICLAC register)
Bristol UK), U-2 OS (U2OS) cells (ATCC HTB-96), HEK293T cells (ATCC CRL-3216), Calu-3 cells (ATCC HTB-55) and primary bronchial human airway epithelial cells (purchased from Epithelix).

No cell line authentication was performed

Cell lines were negative for mycoplasma contamination

None

\section{Human research participants}

Policy information about studies involving human research participants

Population characteristics

Describe the covariate-relevant population characteristics of the human research participants (e.g. age, gender, genotypic information, past and current diagnosis and treatment categories). If you filled out the behavioural \& social sciences study design questions and have nothing to add here, write "See above."

Recruitment

Describe how participants were recruited. Outline any potential self-selection bias or other biases that may be present and how these are likely to impact results.

Ethics oversight

Identify the organization(s) that approved the study protocol.

Note that full information on the approval of the study protocol must also be provided in the manuscript.

\section{Clinical data}

Policy information about clinical studies

All manuscripts should comply with the ICMJE guidelines for publication of clinical research and a completed CONSORT checklist must be included with all submissions.

Clinical trial registration

Study protocol

Data collection

Outcomes
The manuscript reports some data from post-mortem analysis of patients with COVID-19

Note where the full trial protocol can be accessed OR if not available, explain why.

Patients' samples were collected and analysed at the University Hospital of Trieste. Use of these samples for investigation was approved by the competent Joint Ethical Committee of the Regione Friuli Venezia Giulia, Italy (re. 0019072/P/GEN/ARCS)

Observational study 